\title{
Viroporin activity of SARS-CoV-2 Orf3a and Envelope protein impacts viral pathogenicity
}

\author{
Manish Sarkar, M.Sc. ${ }^{1,2,}$, Paul Etheimer $^{3}$, Soham Saha, Ph.D. ${ }^{2, \dagger}$ \\ ${ }^{1}$ Structural Biology Lab 328, Bose Institute, P-1/12, CIT Road Scheme VIIM Kolkata \\ 700054 WB India \\ ${ }^{2}$ Medlnsights, 6 rue de l'église, 02810 Veuilly la Poterie, Aisne, France. \\ ${ }^{3}$ Université de Paris, 85 boulevard Saint-Germain, 75006 Paris, France
}

\section{† Correspondence to:}

Tel: +91-33-25693273

E-mail: sarkarmanish2016@jcbose.ac.in, manish@medinsights.fr, soham@medinsights.fr

†Equal contributions

One Sentence Summary: Membrane permeation of Orf3a is significantly more in SARS-CoV-2 than in SARS-CoV-1 which might contribute to increased viral contagion. 


\section{Abstract}

COVID-19 is caused by SARS-CoV-2 which has affected nearly 220 million people worldwide and death toll close to 5 million as of present day. The approved vaccines are lifesaving yet temporary solutions to such a devastating pandemic. Viroporins are important players of the viral life cycle of SARS-Cov-2 and one of the primary determinants of its pathogenesis. We studied the two prominent viroporins of SARSCoV-2 (i) Orf3a and (ii) Envelope (E) protein from a structural point of view. Orf3a has several hotspots of mutations which has been reported in SARS-CoV-2 with respect to SARS-CoV-1. Mutations in SARS-CoV-2 Orf3a channel forming residues enhances the formation of a prominent the inter-subunit channel, which was not present in the SARS-CoV-1 Orf3a. This enhanced structural feature can be correlated with higher channelling activity in SARS-CoV-2 than in SARS-CoV-1. On the other hand, $E$ protein is one of the most conserved protein among the SARSCoV proteome. We found that the water molecules form networks of electrostatic interactions with the polar residues in the $E$ protein putative wetted condition while no water channel formation was observed in the putative dewetted condition. This aqueous medium mediates the non-selective translocation of cations thus affecting the ionic homeostasis of the host cellular compartments. This ionic imbalance leads to increased inflammatory response in the host cell. Our results shed light into the mechanism of viroporin action, which can be leveraged for the development of antiviral therapeutics. Furthermore, our results corroborate with previously published transcriptomic data from COVID-19 infected lung alveolar cells where inflammatory responses and molecular regulators directly impacted by ion channelling were upregulated. These observations overlap with transcript upregulation observed in diseases having acute lung injury, pulmonary fibrosis and Acute Respiratory Distress Syndrome (ARDS).

Keywords: Orf3a, envelope protein, molecular dynamics, viroporin, ion channeling activity 


\section{Introduction}

The COVID-19 (CoronaVIrus Disease 2019) is a severe acute respiratory syndrome (SARS) caused by a novel pathogenic $\beta$-coronaviral strain, SARS-CoV-2 which has affected millions of people globally creating a huge stir in all aspects of human life. Vaccine has been developed using various technologies by several Pharma giants like AstraZeneca [1], Moderna [2], Pfizer [3,4] along with several other lead candidates in line. The FDA approved vaccines all have similar target or origin and they have their respective drawbacks which are still under investigation. SARS-CoV-2 has a genome encoding 28 proteins which play important roles in several stages of viral pathogenesis [5-8]. The mRNA (Pfizer, Moderna) and the adenoviral vector-based vaccines (Astrazeneca) use epitopes from the spike protein to generate an immunogenic response in the body and thus creating an immunogenic memory. But since spike protein is very much prone to mutations [911], these vaccines might lose their efficacies with the evolving viral genome [12]. So, the other cellular events involved in the viral pathogenesis, which are more conserved phylogenetically, have become an important area of research. Ion channelling activity is one such feature which encompasses viroporins and their counter balancing host cellular responses which range from opposite directional ion flow to downstream disruptions of the host cell signalling pathways [13-15]. The ion channelling activity of SARS-CoV-2 is prominently maintained by two proteins- (i)

Envelope (E) protein $[10,16]$ and (ii) Orf3a protein $[16,17]$. The structure of the pentameric E protein from SARS-CoV-2 has been elucidated by NMR (PDB id: 7K3G) [16] and homology modelling [10] which gives a refined structure of a single channel having selectivity towards cations [18]. Cryo-EM microscopy has given insights into the dimeric structure of Orf3a (PDB id: 6XDC) which has three well 
defined aqueous pathways fit for ion channelling and is a cation selective channel [19]. Ion channelling mechanism of SARS-CoV-2 viroporins potentially leads to ionic imbalance and $\mathrm{pH}$ change of subcellular compartments of the infected host cells causing membrane disruption and intracellular misfunction. Microsomal structures formed of the disrupted host membrane could be utilized in virion assembly and packaging. The E protein localizes in the ERGIC membrane of SARS-CoV-2 [17,20] and SARS-CoV-1 [21] while Orf3a localizes primarily in the endosomal-lysosomal membranes of SARS-CoV-2 [22,23] and in the Golgi Apparatus of SARS-CoV-1 $[24,25]$. Disruption of the ERGIC affects the protein translocation and processing pathways of the host cell causing ER stress [26] while endosomal- lysosomal membrane rupture leads to total breakdown of the host trafficking machinery [13,23]. lonic imbalance and $\mathrm{pH}$ change [27] of the viroporins can be accountable for the release of the virion particles from its organelle of origin . which leads to fatal consequences from a host point of view.

These might lead to inflammatory responses in the host cell which then causes lung failure leading to ARDS which is the reason for most of the fatalities of this viral infection [28]. Amino acid substitutions in the pore lining residues of viroporins might lead to loss or gain in function of the ion channel partially or totally along the course of evolution. The envelope $(\mathrm{E})$ protein is one of the most conserved proteins in coronavirus lineage and that of SARS-CoV-2 is sequentially identical to its SARS-CoV-1 counterpart [10]. Orf3a also shares a high-level sequence similarity with several mutation hotspots which have been identified in SARS-CoV-2 from SARS-CoV-1 [29]. Molecular dynamics simulation is a relatively new technique which helps researchers to understand fine molecular events happening in a system of their interest [30]. In our case, the viroporins are modelled as membrane inserted 
structures which allows solute and solvent movement and thus helps us to elucidate their mechanism of actions using MD simulation.

\section{Materials and methods}

\subsection{Multiple sequence alignment}

In order to assess the conservation among the coronavirus Orf3a-proteins, a proteinprotein BLAST (BLASTp: Basic Local Alignment Search Tool) was performed with the Orf3a protein sequence of SARS-CoV-2 (accession number in QRN50954). Using a threshold of $75 \%$ sequence identity as filters, we aligned the resulting sequences using the online alignment tool Clustal Omega [31] and was visualized with Jalview (www.jalview.org). The sequence alignment, conservation score, quality of alignment, and consensus residue for each position was also obtained.

\subsection{Disparity score and pairwise distance}

Estimates of evolutionary divergence for the different Orf3a protein sequences isolated from different sources (bat, civet, pangolin, bat, SARS-CoV-1, and SARSCoV-2 (accession number: QRN50954.1)) was obtained by estimating the evolutionary tree, pairwise distance, and sequence disparity. Poisson correction models with pairwise deletion for ambiguous sequence sites were used in the calculations. The disparity index, which uses a Monte-Carlo procedure to test homogeneity among the input sequences, is a measure of heterogeneity among sites [32] and was calculated using MegaX [33]. Values greater than 0 indicate the larger differences in amino acid composition biases than expected, based on the evolutionary divergence between sequences and by chance alone. This analysis 
involved 100 amino acid sequences. There was a total of 276 positions in the final dataset.

We estimated the evolutionary divergence between the Orf3a protein sequences using a pairwise distance parameter. A Poisson correction model was used and the rate of variation among amino acid sites was fitted using a gamma distribution (shape parameter $=1$ ). This analysis involved 100 amino acid sequences. The pairwise deletion was used to remove ambiguous sequences [34].

\subsection{Homology modelling of the Orf3a protein and E protein}

The structure of the Orf3a protein of SARS-CoV-2 has been elucidated using cryo-EM microscopy and determined as a dimeric protein (PDB id: 6XDC) [19]. This structure has been used as a template for structure-based homology modeling of its counterpart in SARS-CoV-1. The Cryo-EM structure and the model of the protein from SARS-CoV-1 were further used for analysis.

In our previous study, we modelled the $\mathrm{E}$ protein of SARS-CoV-2 using the NMR structure of E protein from SARS-CoV-1 (PDB-id: 5X29; [10,35]. Another model of E protein was generated using its NMR structure from SARS-CoV-2 (PDBid: 7K3G) [16] to decrease its structural anomalies as analysed using Molprobity. Both the models were used for further analyses.

All the homology modelling procedures have been performed using MODELLER [36] and SWISS-MODEL [37]. Model refinement and further structural fine-tuning of unreliable structural regions were done using the GalaxyWeB server [38]. The structures obtained were validated by scores obtained from the MolProbity $[39,40]$. The structures were chosen by comparing predominantly the different parameters like percentage of Ramachandran favoured and unfavoured residues, 
percentage of favoured and unfavoured rotamers, Mol-Probity score, and Clash

Score, validating the quality of the modelled proteins.

\subsection{Generation of the protein-membrane system}

The transmembrane region of all the proteins was extracted and used for insertion in respective membrane mimics depending on their cellular localization. Orf 3a from SARS-Cov-2 was inserted into an endosome mimicking membrane while its SARS-

CoV-1 counterpart was inserted into a membrane system mimicking the Golgi apparatus. The E protein was inserted into a membrane similar to the ERGIC. Asymmetric lipid compositions were maintained in the endosome and Golgi apparatus mimicking systems. All the membrane insertion processes were performed in the CHARMM-GUI web server [41,42] similar to our previous study [10]. The pore water of each of these channel proteins was removed while preparing the protein-membrane systems in CHARMM-GUI. The lipid compositions of each system corresponding to their inserted proteins are listed as follows:

Table 1: Lipid composition of different membrane components of intracellular compartments (endosome, Golgi and ERGIC)

\begin{tabular}{|c|c|c|c|}
\cline { 2 - 4 } & $\begin{array}{c}\text { Orf3a of SARS- } \\
\text { CoV-2 }\end{array}$ & $\begin{array}{c}\text { Orf3a of SARS- } \\
\text { CoV-1 }\end{array}$ & E protein \\
\cline { 2 - 4 } & \multicolumn{3}{|c|}{ Intracellular compartments } \\
\hline Lipids & Endosome & Golgi & ERGIC \\
\hline POPC & 120 & 144 & 94 \\
\hline POPE & 44 & 84 & Not present \\
\hline PSM & 60 & Not present & 28 \\
\hline Cholesterol & 120 & 72 & Not present \\
\hline bGMP & 28 & Not present & \\
\hline
\end{tabular}




\subsection{Molecular dynamics simulations using NAMD and VMD}

The protein membrane systems were solvated using a $12 \AA$ thick patch of TIP3P [43] waters at both sides of the protein bilayer complex along the $z$ axis, and a uniform hexagonal area was maintained in the $x-y$ plane. The $\mathrm{K}+$ ion was added to the solvated system as required to mimic $0.15 \mathrm{M} \mathrm{KCl}$ which is similar to our physiological concentration of $\mathrm{K}+$ ion. The structural models of proteins and lipids were presented using the CHARMM36 force field parameters $[44,45]$ and NAMD $2.12[46,47]$ was used to run the molecular dynamics (MD) simulations. Firstly, the energy of each system was minimized and then equilibrated using the NVT ensemble for $40 \mathrm{ps}$. The integration time step was kept at $1 \mathrm{fs}$ with harmonic restraints of $10 \mathrm{kcal} \mathrm{mol}^{-1} \AA^{-2}$ on the protein atoms and $5 \mathrm{kcal} \mathrm{mol}^{-1} \AA^{-2}$ on the lipid headgroups. These are the first two steps of minimization and initial equilibration of the simulation system. Several cycles of NPT equilibration (four or more) were carried out after the first two steps with reducing force constants in each cycle to relax the restraints on the protein-membrane simulation system. The entire energy minimization and equilibration steps add up to around 2.25 ns for each simulation run. The minimized and equilibrated protein-membrane system was then simulated for 5 ns using an integrating time step of $2 \mathrm{fs}$, constraining all $\mathrm{H}$-containing bonds by the SHAKE algorithm [48]. The total sampling time of the trajectories altogether added to $\sim 20 \mathrm{~ns}$. Langevin dynamics was used in all the simulations to keep the temperature constant at $303 \mathrm{~K}$ with a damping coefficient of $1 \mathrm{ps}^{-1}$, and the Langevin piston method was used in NPT ensembles to keep the pressure constant at 1 atm with a coupling constant of TP $=0.5 \mathrm{ps}$ [49]. In all these simulations, short-range nonbonded interactions were switched off between 10 and $12 \AA$. The Particle Mesh Ewald method [50] was employed with a grid size of $1 \AA$ for the estimation of long- 
range electrostatic interactions. The total energy of the simulation system, number of H-bonds, RMSD, RMSF and solvent accessible surface area (SASA) of specific pore forming residues were analysed with respect to time steps as obtained from the results of the NAMD simulation in VMD [51] interface and snapshots of the timesteps were represented and visualized using Chimera 1.10 [52].

\subsection{Transcriptomic analysis}

Transcriptomic data was reanalyzed from the following source: Katsura et al., 2020 Cell Stem Cell [53]. The data is derived from whole genome RNA sequencing from modular alveolo-sphere culture system of human alveolar type 2 cells/pneumocytes derived from primary lung tissue [53]. Data was downloaded from Gene Expression Omnibus library [ID: GSE152586] and preprocessing of the fastq files were performed. Details of data extraction and experimental procedures are available in the original publication: Katsura et al., 2020 Cell Stem Cell [53]. The DESeq2 package in $\mathrm{R}$ BioConductor (http://www.bioconductor.org/packages/release/bioc/html/DESeq2.html) was used to analyze the data. The normalized data was used for visualization, and differential analysis of the count data [54]. The DESeq2 data class consists of a count matrix with rows corresponding to genes and columns denoting experimental samples (control and COVID-19). For dimensional reduction and outlier identification, we performed a principal component analysis (PCA) on the DESeq2 data class of count reads. The details of DESeq2 pipeline is discussed in detail in Love et al., 2014 Genome Biology [54]. Briefly, DESeq2 package model the data counts on the count matrix using a gamma-Poisson distribution with mean (normalized concentration of cDNA fragments from the gene in a sample). The size factors are determined by the 
median-of-ratios method. For each gene, a generalized linear model (GLM), which returns overall expression strength of the gene, $\log _{2}$ of the fold change (LFC) between the two groups compared. The $p$ values of comparison between control and infected samples are adjusted for multiple testing using the Benjamini and Hochberg procedure.

To identify the processes encoded by the upregulated genes, we used the publicly available protocol in Metascape (www.metascape.org/; [55]). We annotated the functions encoded by the genes using the following gene ontology enrichment: Biological processes, Cellular components, Molecular components, KEGG pathway and Reactome pathways. Metascape combines functional enrichment, interactome analysis, gene annotation, and membership search to leverage over 40 independent knowledgebases. The minimum overlap was kept at 3 , the p value cutoff at 0.01 and the minimum enrichment was kept at 1.5. The network type was set at full network, network edges defined by confidence of the highest threshold (90\%).

\subsection{Statistical analysis}

For statistical comparisons, we have used Kolmogorov-Smirnov (KS) Test for comparing the cumulative distributions and unpaired students' t-test for comparison between different conditions. The $p$-values reported in this paper consider $p<0.05$ to be statistically significant. 


\section{Results}

\subsection{Sequential analysis of the Orf3a protein sequences across the phylogeny}

A BLASTp search run was performed which resulted in 100 sequences of Orf3a from different origins, out of which we compared 15 sequences ranging from SARS-CoV-1 to SARS-CoV-2 (Fig. 1A). The aligned sequences have sequence identities of $70 \%-100 \%$ and were taken from SARS-CoV-1 (sp|P59632.1), bats (Cp/Yunnan2011; Rf1/2004; Rp/Shaanxi2011), civet (ORF3a Civet SARS-like CoV_007/2004), pangolin and human SARS-CoV-2 Orf3a.. These candidate Orf3aproteins from different origins were plotted as the evolutionary distance, which showed two specific phylogenetic sub-lineages (Fig. 1B). The first cluster (colors: blue, green) comprises of pangolin (QIA48624.1, QIA48633.1), rat RaTG13 (QHR63301.1) and human SARS-CoV-2 (QNO67524.1, QQY29507), while the second (colors: grey, brown) comprises of human SARS-CoV-1 (P59632.1, AAT52339.1, YP_009825052.1 and AAU04635.1) and bats (ATO98232.1, AT098158.1, AGC74172.1, ABD75316.1, AGC74166.1 and ADE34780.1). This indicates that Orf3a sequences cluster in two distinct "clades" and recent SARSCoV-2 Orf3a sequences are closer to those isolated from pangolins than from human SARS-CoV-1 (Fig. 1B). Consistently, there was an increase in the pairwise distance (Fig. 1C) and disparity index (Fig. 1D) among the recent sequences of Orf3a. This increase in the distance was notable in the pangolin Orf3a sequences and bat RaTG13 sequence. These sequences remained closer to human isolates of SARS-CoV-2 Orf3a by sequence similarity (Fig. 1C, D). A higher value of the disparity index and pairwise distance indicated larger differences in amino acid composition than expected in recent sequences of Orf3a as compared to older ones from SARS CoV-1. 


\subsection{Molecular dynamics simulation of the TM region of Orf3a (40-125) from SARS-CoV-2 and SARS-CoV-1 in respective membrane mimicking systems}

The SARS-CoV-2 Orf3a dimeric protein structure has been determined using cryo-EM at 2.9 angstroms resolution (PDB id: 6XDC) [19]. The transmembrane region of the protein ranges from 40 to 125 th residue of the protein. We performed membrane insertion of the truncated structure of Orf3a (40-125) using CHARMMGUI. It comprises of lipid components mimicking the human endosomal membrane (Table 1). Then a molecular dynamics simulation of 5 ns was performed using NAMD to understand the channelling activity of the upper and inter-subunit channels of the protein (Suppl. Movie 1). We observed the upper subunit channel in the protein-membrane system (Fig. 2A-black dotted circle). The water dynamics are observed at regular intervals of $0.5 \mathrm{~ns}$ for $2 \mathrm{~ns}$ from the initial timestep starting at 0 ns (Fig. 2B-i), 0.5 ns (Fig. 2B-ii), 1 ns (Fig. 2B-iii), 1.5 ns (Fig. 2B-iv), and 2 ns (Fig. 2B-v). Similarly, we observed the inter-subunit channel (Fig. 2C-black dotted circle) at similar timesteps to the upper subunit channel (Fig. 2D-i-v). We calculated the number of H-bonds (Fig. 2E), RMSD (Fig. 2F), total energy (Fig. 2G), and RMSF (Fig. $2 \mathrm{H}$ ) for $5 \mathrm{~ns}$ of the simulation. The RMSD remains below 2.5 angstroms ((Fig. $2 \mathrm{~F}$ ), indicating that the protein-membrane system has low structural variability in $5 \mathrm{~ns}$ of simulation. In addition, the total energy of the system remains largely unchanged at $-5.7 \times 104 \mathrm{kcal} / \mathrm{mol}$ (Fig. 2G) throughout the time period of the simulation.

The SARS-CoV-1 Orf3a structure is not available from experimental techniques and so we homology modelled the structure taking the cryo-EM structure of its counterpart (PDB id: 6XDC) in SARS-CoV-2 as a template. The final structure of dimeric Orf3a from SARS-CoV-1 was validated using Molprobity. Similar to the 
previous pipeline, the structure was truncated to obtain the TM region (40-125) of Orf3a and inserted into a Golgi Apparatus membrane mimic consisting of respective lipid components in CHARMM-GUI (Table 1). Then we performed an all atom MD simulation using NAMD to understand the channelling activity of the upper and intersubunit channels of the protein from SARS-CoV-1 (Suppl. Movie 2). We observed the upper subunit channel in the protein-membrane system (Fig. 3A-black dotted circle). The water dynamics are observed at regular intervals of $0.5 \mathrm{~ns}$ for 2 ns from the initial timestep starting at 0 ns (Fig. 3B-i), 0.5 ns (Fig. 3B-ii), 1 ns (Fig. 3B-iii), 1.5 ns (Fig. 3B-iv), and 2 ns (Fig. 3B-v). Similarly, we observed the inter-subunit channel (Fig. 3C-black dotted circle) at similar timesteps to the upper subunit channel (Fig. 3D-i-v). We calculated the number of $\mathrm{H}$-bonds (Fig. 3E), RMSD (Fig. 3F), total energy (Fig. 3G), and RMSF (Fig. 3H) for 5 ns of the simulation. The RMSD remains below 2.5 angstroms ((Fig. 3F), indicating that the protein-membrane system has low structural variability in 5 ns of simulation. In addition, the total energy of the system remains largely unchanged at $-5.4 \times 104 \mathrm{kcal} / \mathrm{mol}$ (Fig. 3G) throughout the time period of the simulation.

\subsection{Mutability of Orf3a in SARS-CoV-2 contributes to the distinct architecture in the pore forming regions of the protein than its SARS-CoV-1 counterpart}

The inter-subunit channel of Orf3a in SARS-CoV-2 forms a prominent pore structure (Fig. 2D-iii, iv, v; Suppl. Movie 1) while no such feature is observed in the similar region of SARS-CoV-1 counterpart (Fig. 3D-iii, iv, v; Suppl. Movie 2). Multiple sequence alignment of the Orf3a TM region from SARS-CoV-1 and SARS-CoV-2 showed that several mutations were observed in the latter (A64T, N66K, Q78H) (Fig. 4A). These mutations happen to be in the region of the pore forming domain which is 
responsible for the formation of the upper and inter-subunit channels as observed in the Cryo-EM structure of Orf3a. So, these amino acids might be crucial for the unique architecture of the pore pathways in SARS-CoV-2. The structures of the Orf3a proteins from both strains were superimposed to observe the pore-forming residues of the inter-subunit channel (Fig. 4B, 4C). We observed that the intersubunit channel from SARS-CoV-1 does not allow passage of water molecules through it (Fig. 4D-blue arrow, Suppl. Movie 2)) but that from SARS-CoV-2 allows cytosolic passage of water molecules (Fig. 4E-blue arrow, Suppl. Movie 1). This functional gain in SARS-CoV-2 Orf3a was analysed based on the pore-lining residues of the inter-subunit channel along with their acquired mutations in SARSCoV-2 over SARS-CoV-1. We calculated the individual Solvent Accessible Surface Areas (SASAs) and RMSFs of the pore-lining residues of the inter-subunit channel of Orf3a proteins for 5 ns of MD simulation (SARS-CoV-1: Fig. 4F, SARS-CoV-2: Fig. 4G). We observed a significant change of SASA at the 64th (blue line) and 66th residue (dark green line) between SARS-CoV-1 (Fig. 4F) and SARS-CoV-2 (Fig. 4G). So, we calculated the total SASA of the pore-lining residues with their respective contributions where the total SASA in SARS-CoV-2 was found to be significantly higher than in SARS-CoV-1 (Fig. 4H) indicating a higher probability of water passage through the inter-subunit channel. Pore estimation of the proteins validated that Orf3a from SARS-CoV-1 (Fig. 4I) does not have a pore-forming region of the reported inter-subunit channel (Fig. 4I-blue arrow) while that of SARS-CoV-2 has a well-defined pore in the corresponding region (Fig. 4J-blue arrow). The contribution of the acquired mutations of the pore-lining residues in SARS-CoV-2 over SARS-CoV-1 in the SASA and thus the formation of the inter-subunit channel were analysed (Fig. 4K). It was found out that the A64T and N66K mutations were 
significantly contributing to this higher SASA in SARS-CoV-2 than in SARS-CoV-1 which is in tune with our previous result (Fig. 4K). The total energy of the proteinmembrane system from SARS-CoV-2 was found to be significantly lower than that of the SARS-CoV-1 (Fig. 4L) which is directly proportional to the structural and functional stability of the virus.

\subsection{Molecular dynamics of the TM region of SARS-CoV-2 Envelope protein in an ERGIC membrane mimic}

The pentameric structure of the Envelope $(E)$ protein from the SARS-CoV-2 has been modelled (PO model) and its viroporin activity through the single channel formed by its TM region (8-40) has been analysed using in silico approaches [10]. The pentameric TM region (8-40) of the E protein model from our previous study (was complexed with an ERGIC mimicking membrane using respective lipid components (Table 1) in CHARMM-GUI (Fig. 5A). The protein-membrane complex was equilibrated energetically followed by 5 ns of MD simulation in NAMD to analyse the continuous water channel formation through the proposed pore (Suppl. Movie 3). The water dynamics are observed at several intervals for 2 ns from the initial timestep starting at 0 ns (Fig. 5B-i), 0.5 ns (Fig. 5B-ii), 1 ns (Fig. 5B-iii), 1.1 ns (Fig. 5B-iv), 1.2 ns (Fig. 5B-v), 1.3 ns (Fig. 5B-vi), 1.4 ns (Fig. 5B-vii), 1.5 ns (Fig. 5B-viii), and 2 ns ((Fig. 5B-ix). It was observed that from 1 ns to 1.5 ns that the water molecules reach the proposed bottleneck region [10] formed by the F26 residues inside the pore of the $\mathrm{E}$ protein (Fig. 5B-iii-viii). We calculated the number of $\mathrm{H}$ bonds (Fig. 5C), RMSD (Fig. 5D), total energy (Fig. 5E), and RMSF (Fig. 5F) for 5 ns of the simulation. The RMSD remains well below 5 angstroms (Fig. 5D), indicating that the protein-membrane system has high structural stability for $5 \mathrm{~ns}$ of simulation. 
In addition, the total energy of the system remains relatively unfluctuating around $3.2 \times 10^{4} \mathrm{kcal} / \mathrm{mol}$ (Fig. 5E) throughout the time period of the simulation.

\subsection{Envelope protein of SARS-CoV-2 undergoes dynamic structural changes}

The E protein structure modelled from its solid-state NMR structure (NS model) (PDB id: 7K3G, [16]) from SARS-CoV-2 was inserted into an ERGIC mimicking membrane using respective lipid components (Table 1) in CHARMM-GUI (Fig. 6A). The protein-membrane system was equilibrated energetically followed by 5 ns of MD simulation in NAMD to analyse the continuous water channel formation through the central pore (Suppl. Movie 4). The water dynamics are observed at regular intervals of $0.5 \mathrm{~ns}$ for $2 \mathrm{~ns}$ from the initial timestep starting at 0 ns (Fig. 6B-i), 0.5 ns (Fig. 6Bii), 1 ns (Fig. 6B-iii), 1.5 ns (Fig. 6B-iv), and 2 ns (Fig. 6B-v). We compared the RMSD (Fig. 6C) and total energy (Fig. 6D), for 5 ns of the simulation for both the proposed wetted (PO model) and dewetted (NS model) states. There was no significant difference in the RMSD among the two molecular dynamics simulations of SARS-CoV-2 E protein (Fig. 6C) which supports the stability of the protein membrane systems. However, we observed a significant increase of total energy in the proposed wetted state (PO Model) as compared to the proposed dewetted state (NS model) (KS test; $p<0.0001$; Fig. 6D, E). A significant increase in the energy profile due to electrostatic interactions in the wetted state than in the dewetted state was observed between the two E protein systems (Fig. 6F). The wetted state showed an increase in the Vander Waals energies than in the dewetted state (Figure $6 \mathrm{G})$. These changes in energies corroborates with the passage of water molecules in the dewetted state. Kinetic energies of both the states were significantly similar (Fig. $6 \mathrm{H}$ ) and the energies due to bond angles (Fig. 6I), dihedral angles (Fig. 6J) and 
bond lengths (Fig 6K) remained unchanged. The contribution to the total energy change between the proposed dewetted and wetted states of the E protein due to electrostatic interactions is more than that of the Vander Waals interactions (Fig. 6L). All these results validate our previous structural observations [10] that E protein can indeed remain in dynamic equilibrium and shift between dewetted and wetted conditions during its functionality.

\subsection{Upregulated genes in COVID condition reflects cellular processes impacted}

\section{by ion channelling activity}

We used whole genome RNA sequencing data [53] to explore genes upregulated in SARS-CoV-2 infection, and whether they could be impacted by changes in cellular ionic homeostasis. We employed principal component analysis (PCA) as an exploratory data analysis step (Fig.7A). PCA analysis (Fig.7A) suggested that uninfected controls and SARS-CoV-2 infected samples were mutually orthogonal to each other, suggesting that gene expression levels were indeed due to the infection. The first component explained $53 \%$ of the observed variance in the expression patterns. We further looked into the proportion of upregulated and downregulated genes (Fig 7B, 7C), and found 563 significantly upregulated genes and 75 significantly downregulated genes. The log of fold change (LFC) after the DESEQ2

pipeline was set at a minimum of 2 , and adjusted $p$-value was set at 0.01 . The top 50 upregulated and downregulated genes are shown in Suppl. Fig. 1. PRKAA1 is upregulated in the infected samples, albeit it did not clear the threshold of LFC > 2 (Fig. 7D) and interestingly has been shown to regulate ion channeling activity of host cell [56]. We also observed significant upregulation in immune modulatory genes like CD40, IFNL1, IFNL2, IFNL3, IL12A, IL33, IL6 and NFkB1 (Fig. 7E). Among the 
downregulated genes were HSP90AB1, HSP90AA1 and HSP90B1 (Fig. 7F). In our analysis, we focused on those genes only that could be impacted or otherwise impact ion channeling and ionic concentration. In our analysis, $88 \%$ of the genes were upregulated while 12\% were downregulated (Fig. 7G). In order to understand what cellular and molecular functions could be impacted by the upregulated genes, we constructed a gene network analysis using Metascape (Fig. 7H). The major functions implicated are Defense response to virus, Type II interferon signaling, Immune response regulating signaling pathway, Response to IFN- $\beta$, Regulation of cytokine production, Response to IFN- $\gamma$, Lymphocyte activation, SARS-CoV-2 innate

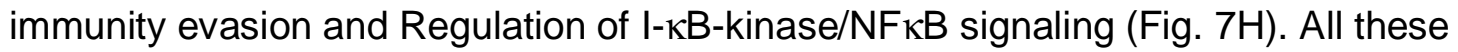
processes imply the active participation and activation of the host defense system in case of a viral infection. We also evaluated the functional significance of proteinprotein interactions of the upregulated genes and found that the following functions were enriched: Defense response to virus, IFN- $\alpha / \beta$ signaling, Cytokine signaling, post translational protein phosphorylation, Calcium signaling pathway- $\mathrm{G} \alpha(\mathrm{q})$ signaling, PI3K-Akt-mTOR signaling, Exocytosis and Complement cascades (Fig. 7I). Indeed, a lot of these functionalities could be directly or indirectly affected by ionic imbalances in the cell. These observations provide strength to our hypothesis that ion channeling activity by viroporins could be responsible for enhanced pathogenesis and host cell responses in SARS-CoV-2.

\section{Discussion}

lon channelling activity is an important cellular event taking place in all organisms, from unicellular prokaryotes to multicellular eukaryotes like humans. 
Human cellular organization and mechanisms of varied physiological events are directly or indirectly influenced by ion channels, which are mostly specific for the type of ion it transports. Almost all families of viruses encode one or more ion channel proteins which integrate in the host membrane and regulate key viral life cycle events like virion maturation, assembly and release. Viroporins oligomerizes in the host membranes, leading to formation of permeable hydrophilic pores [13,57], which alters cellular ionic homeostasis in hosts. It leads to membrane depolarization and disruption of organelle architecture via membrane remodelling events, alteration of $\mathrm{Ca}^{2+}$ homeostasis [58] and protein trafficking. Thus, viroporin is an important determinant of the viral pathogenicity.

COVID-19 is a viral infection which shows relatively higher aggravation of contagion than its previous strains. Compared to the previous SARS-CoV strains, SARS-CoV-2 demonstrates a plethora of mutations across its entire genome [59]. This increased pathogenicity has been linked to one or more mutations in the critical players of the viral machinery leading to their structural and functional modifications [60]. Some of the reported structural changes observed in the Spike (S) protein $[61,62]$, the replication machinery (RdRp, Nsp7 and 8) [63] and the main protease, $M^{\text {pro }}[64]$ can be correlated with higher infectivity and pathogenesis. However, the impact of the SARS-CoV-2 viroporins on the host functionality remains poorly elucidated. We looked into the membrane permeation and channel-forming mechanism of the Orf3a and E protein from SARS-CoV-2 and SARS- CoV-1.

Viroporins from a wide spectrum of virus families impact cellular physiology of the host cell. One of the most studied viroporins is the M2 channel of the influenza virus which is essential for viral replication and homeostasis. The M2 channel allows $\mathrm{K}+$ ion influx and disrupts the ionic homeostasis of high $\mathrm{Na}+$ and low $\mathrm{K}+$ 
concentration in the late endosomes. It also acts as a proton channel in the TGN ( $\mathrm{pH} 6)$ which affects downstream protein trafficking machinery [65]. NS4A channel of HCV localizes on the mitochondrial membrane and disrupts mitochondrial architecture by causing ionic imbalance in the organelle lumen [66]. Viroporins activate apoptosis through the mitochondrial pathway via formation of apoptosome with pro-caspase 9 and apoptosis protease-activating factor-1 [67]. P7 viroporin of $\mathrm{HCV}$ is a gated proton channel which causes $\mathrm{H}+$ efflux, resulting in IL-1 $\beta$ production [68] The envelope (E) protein of SARS-CoV-2 has been reported to rescue growth of $\mathrm{K}+$-uptake deficient bacteria thus supporting its $\mathrm{K}+$ conductivity. Additionally, it acts as a proton channel and causes bacterial cell death due to increased membrane permeabilization [18].

However, the exact molecular mechanism of these ion channelling events have not been explored from a structural point of view. Our results demonstrate salient structural features which might determine how the viroporin functions. First, we show that Orf3a has an apparent gain of a structural feature in SARS-CoV-2 which differentiates it from that of SARS-CoV-1. Hydrophilic pore formation is one of the fundamental features of a viroporin [13]. We show formation of hydrophilic pore via water channel formation which could be correlated with formation of ionic transfer mediums across the membranes. Such a passage medium through the inter-subunit channel of Orf3a in SARS-CoV-2 is unique and not observed in its SARS-CoV-1 counterpart. This implies a higher hydrophilic permeation pathway and channelling of ions through the protein in SARS-CoV-2 than in SARS-CoV-1. Our selection of mutated amino acids corroborates with a previous study showing alteration of Orf3a structure due to its mutability at several positions [29]. The change of primary localizations of Orf3a from ER-Golgi compartment in SARS-CoV-1 to late 
endosomal-lysosomal compartment in SARS- CoV-2 [17] is an energeticallysupported configuration, as Orf3a in endosomal-mimic had lower energies compared to the Orf3a in Golgi-membrane-mimic. Secondly, we show that conserved E-protein can form dynamic states for its functionality, as we had speculated previously [10]. While continuous water channel formation was visible in the hydrophilic pore of our homology model [10], we observed that E protein modelled from its solid-state NMR structure [16] did not show water channel formation despite having sufficient pore radius for hydrophilic pore formation.

Analysis of energy change is supportive of the fact that $E$ protein can remain in an inactivated state (dewetted condition) and it undergoes activation through local conformational changes of the channel forming residues. These local movements facilitate water movement (wetted condition) through its pentameric hydrophilic pore via electrostatic interactions between the residues and the incoming water molecules. The movement of water molecules through a channel is a continuous event of making and breaking of electrostatic interactions thus consuming energy during the process. This is depicted in our result as the change in total energy with the energy due to electrostatic interactions as its primary contributor. Therefore, a tight regulation of the water movement depends directly on its structural conformations.

The question remains, what impact do these viroporins impart at a physiological level? Indeed, our studies are in silico and have limitations of being non-experimental from an in vitro and in vivo standpoint. However, the impact of ionic imbalances in cellular micro-environment as a result of viral infections and viroporins have been studied in great detail earlier. One immediate observation comes from the previous SARS strain, the SARS-CoV-1. It was shown that E protein 
localized in the ERGIC membrane, and facilitated the movement of Ca2+ ions into the cytosol [69]. On the other hand, the Orf3a localized at the Golgi apparatus and the plasma membrane, transported $\mathrm{K}+$ ions [70]. A proper regulation of airway epithelial ionic balance is indispensable for healthy homoeostasis in the lungs. A tight regulation of cationic and anionic ion channels controls the ionic homeostasis in the airways which can be correlated to complex pathological features in lung diseases [71]. Viroporins localized in the subcellular membranes of these lung airway epithelial cells is the primary cause of ionic imbalance and thus can be potential therapeutic targets against ARDS, which is the primary reason for fatality in SARS-CoV-2 infection [72,73]. Transcriptomics analysis from patient samples affected with SARS-CoV-2 showed an upregulation in inflammatory response mediated by several interleukins and interferons [74] which are probably regulated by NFкB [75]. Increase in CD40 [76], IL-6 [77], IL-12 [78] and IL-33 [79] transcripts strongly correlate with similar expression patterns of differentially expressed genes in Acute Lung Injury, ARDS and pulmonary fibrosis. NF-kB signalling has also been shown to be activated and induce inflammatory cytokines and chemokines, including IL-1b, IL-18, and IL-8 [80-82]. AMPK is a master regulator of a wide spectrum of ion channels, carrier proteins and symporter-pumps [56], differential expression of which can impact their stimulatory and inhibitory effects [83]. These channels, carrier proteins and/or pumps mediate the primary host cell response against viroporin action. Downregulation of ion channels are also known to be impacted by their interactions with Hsp proteins such as Kv7.4, a voltage gated potassium channel is downregulated which is mediated by a decrease in its interaction with Hsp90 [84]. Indeed, Hsp90, being a part of the protein folding machinery show lower expression levels due to disruption of the ERGIC and endosomal compartment which are the 
two important checkpoints of protein synthesis and quality control. This is in line with our initial membrane disruption hypothesis as a result of change in ionic balance of the cell. In our study, E protein-mediated Ca2+ and K+ leakage, and Orf3-mediated $\mathrm{K}+$ efflux causes ionic imbalance activating the NLRP3 inflammasome. The activation of NLRP3 inflammasome directly correlates with the observed viroporin activity $[70,85]$. Ionic imbalance in cells can promote build up of reactive oxygen species (ROS) in the mitochondria, providing indirect to activation of NLRP3 [70]. Our multivariate study on SARS-CoV-2 viroporins gives valuable structural insights into their mechanism of actions. We have elucidated the importance of Orf3a and E protein in COVID-19 pathogenesis on a structure-function association, potentially translating to changes in the transcriptome of the host cell. Further investigation along these lines can reveal potential therapeutic strategies against SARS-CoV-2.

\section{Authorship contribution statement}

Manish Sarkar \& Soham Saha (co-correspondence): Study design, structural modelling, molecular dynamics and analysis, bioinformatics. MS and SS drafted the manuscript and made the final figures.

Paul Etheimer: Designed analysis automation for whole genome metagenome analysis using DeSEQ2 pipeline and performed the analysis on the transcriptomic data.

\section{Declaration of competing interest}

Authors declare no competing interests. The entire research work was performed during the nation-wide lockdown during the 3rd and 2nd wave of the Covid-19 pandemic in France and India respectively. Only publicly available libraries, servers, and resources were employed for the entire study. All data in the main text or the supplementary materials are available upon request. 


\section{Acknowledgements}

MS is funded by the DST-INSPIRE Ph.D. fellowship by the Govt. of India. SS is the founder of Medlnsights. The funding agencies had no role in the idea and experimental design, model execution and evaluation, and drafting figures and manuscript.

\section{Appendix. Supplementary data}

\section{Supplementary Figure 1: supplement to Figure 7}

Top 50 significantly upregulated (dark green) and downregulated (dark red) which have adjusted $p$-value of $<0.01$ and LFC $>2$.

Supplementary Movie 1: Molecular dynamics of TM- region (40-125) of Orf3a from SARS-CoV-2 inserted into a late endosomal-lysosomal membrane mimic.

Supplementary Movie 2: Molecular dynamics of TM- region (40-125) of Orf3a from SARS-CoV-1 inserted into a Golgi Apparatus membrane mimic.

Supplementary Movie 3: Molecular dynamics of TM- region (8-40) of Envelope (E) protein from SARS-CoV-2 inserted into an ERGIC membrane mimic. The template of the modelled $E$ protein is the NMR structure of the $E$ protein from SARS-CoV-1 (PDB id: 5X29).

Supplementary Movie 4: Molecular dynamics of TM- region (8-40) of Envelope (E) protein from SARS-CoV-2 inserted into an ERGIC membrane mimic. The template of the modelled E protein is its NMR structure from SARS-CoV-2 (PDB id:7K3G).

\section{References}

[1] M. Voysey, S.A.C. Clemens, S.A. Madhi, L.Y. Weckx, P.M. Folegatti, P.K. Aley, B. Angus, V.L. Baillie, S.L. Barnabas, Q.E. Bhorat, S. Bibi, C. Briner, P. Cicconi, A.M. Collins, R. Colin-Jones, C.L. Cutland, T.C. Darton, K. Dheda, C.J.A. Duncan, K.R.W. Emary, K.J. Ewer, L. Fairlie, S.N. Faust, S. Feng, D.M. Ferreira, A. Finn, A.L. Goodman, C.M. Green, C.A. Green, P.T. Heath, C. Hill, H. Hill, I. Hirsch, S.H.C. Hodgson, A. Izu, S. Jackson, D. Jenkin, C.C.D. Joe, S. Kerridge, A. Koen, G. Kwatra, R. Lazarus, A.M. Lawrie, A. Lelliott, V. Libri, P.J. Lillie, R. Mallory, A.V.A. Mendes, E.P. Milan, A.M. Minassian, A. McGregor, H. Morrison, Y.F. Mujadidi, A. Nana, P.J. O'Reilly, S.D. Padayachee, A. Pittella, E. Plested, K.M. Pollock, M.N. Ramasamy, S. Rhead, A.V. Schwarzbold, N. Singh, A. Smith, R. Song, M.D. Snape, E. Sprinz, R.K. Sutherland, R. 
Tarrant, E.C. Thomson, M.E. Török, M. Toshner, D.P.J. Turner, J. Vekemans, T.L. Villafana, M.E.E. Watson, C.J. Williams, A.D. Douglas, A.V.S. Hill, T. Lambe, S.C. Gilbert, A.J. Pollard, M. Aban, F. Abayomi, K. Abeyskera, J. Aboagye, M. Adam, K. Adams, J. Adamson, Y.A. Adelaja, G. Adewetan, S. Adlou, K. Ahmed, Y. Akhalwaya, S. Akhalwaya, A. Alcock, A. Ali, E.R. Allen, L. Allen, T.C.D.S.C. Almeida, M.P.S. Alves, F. Amorim, F. Andritsou, R. Anslow, M. Appleby, E.H. Arbe-Barnes, M.P. Ariaans, B. Arns, L. Arruda, P. Azi, L. Azi, G. Babbage, C. Bailey, K.F. Baker, M. Baker, N. Baker, P. Baker, L. Baldwin, I. Baleanu, D. Bandeira, A. Bara, M.A.S. Barbosa, D. Barker, G.D. Barlow, E. Barnes, A.S. Barr, J.R. Barrett, J. Barrett, L. Bates, A. Batten, K. Beadon, E. Beales, R. Beckley, S. Belij-Rammerstorfer, J. Bell, D. Bellamy, N. Bellei, S. Belton, A. Berg, L. Bermejo, E. Berrie, L. Berry, D. Berzenyi, A. Beveridge, K.R. Bewley, H. Bexhell, S. Bhikha, A.E. Bhorat, Z.E. Bhorat, E. Bijker, G. Birch, S. Birch, A. Bird, O. Bird, K. Bisnauthsing, M. Bittaye, K. Blackstone, L. Blackwell, H. Bletchly, C.L. Blundell, S.R. Blundell, P. Bodalia, B.C. Boettger, E. Bolam, E. Boland, D. Bormans, N. Borthwick, F. Bowring, A. Boyd, P. Bradley, T. Brenner, P. Brown, C. Brown, C. Brown-O'Sullivan, S. Bruce, E. Brunt, R. Buchan, W. Budd, Y.A. Bulbulia, M. Bull, J. Burbage, H. Burhan, A. Burn, K.R. Buttigieg, N. Byard, I. Cabera Puig, G. Calderon, A. Calvert, S. Camara, M. Cao, F. Cappuccini, J.R. Cardoso, M. Carr, M.W. Carroll, A. Carson-Stevens, Y. de M. Carvalho, J.A.M. Carvalho, H.R. Casey, P. Cashen, T. Castro, L.C. Castro, K. Cathie, A. Cavey, J. Cerbino-Neto, J. Chadwick, D. Chapman, S. Charlton, I. Chelysheva, O. Chester, S. Chita, J.-S. Cho, L. Cifuentes, E. Clark, M. Clark, A. Clarke, E.A. Clutterbuck, S.L.K. Collins, C.P. Conlon, S. Connarty, N. Coombes, C. Cooper, R. Cooper, L. Cornelissen, T. Corrah, C. Cosgrove, T. Cox, W.E.M. Crocker, S. Crosbie, L. Cullen, D. Cullen, D.R.M.F. Cunha, C. Cunningham, F.C. Cuthbertson, S.N.F. Da Guarda, L.P. da Silva, B.E. Damratoski, Z. Danos, M.T.D.C. Dantas, P. Darroch, M.S. Datoo, C. Datta, M. Davids, S.L. Davies, H. Davies, E. Davis, J. Davis, J. Davis, M.M.D. De Nobrega, L.M. De Oliveira Kalid, D. Dearlove, T. Demissie, A. Desai, S. Di Marco, C. Di Maso, M.I.S. Dinelli, T. Dinesh, C. Docksey, C. Dold, T. Dong, F.R. Donnellan, T. Dos Santos, T.G. dos Santos, E.P. Dos Santos, N. Douglas, C. Downing, J. Drake, R. Drake-Brockman, K. Driver, R. Drury, S.J. Dunachie, B.S. Durham, L. Dutra, N.J.W. Easom, S. van Eck, M. Edwards, N.J. Edwards, O.M. El Muhanna, S.C. Elias, M. Elmore, M. English, A. Esmail, Y.M. Essack, E. Farmer, M. Farooq, M. Farrar, L. Farrugia, B. Faulkner, S. Fedosyuk, S. Felle, S. Feng, C. Ferreira Da Silva, S. Field, R. Fisher, A. Flaxman, J. Fletcher, H. Fofie, H. Fok, K.J. Ford, J. Fowler, P.H.A. Fraiman, E. Francis, M.M. Franco, J. Frater, M.S.M. Freire, S.H. Fry, S. Fudge, J. Furze, M. Fuskova, P. Galian-Rubio, E. Galiza, H. Garlant, M. Gavrila, A. Geddes, K.A. Gibbons, C. Gilbride, H. Gill, S. Glynn, K. Godwin, K. Gokani, U.C. Goldoni, M. Goncalves, I.G.S. Gonzalez, J. Goodwin, A. Goondiwala, K. Gordon-Quayle, G. Gorini, J. Grab, L. Gracie, M. Greenland, N. Greenwood, J. Greffrath, M.M. Groenewald, L. Grossi, G. Gupta, M. Hackett, B. Hallis, M. Hamaluba, E. Hamilton, J. Hamlyn, D. Hammersley, A.T. Hanrath, B. Hanumunthadu, S.A. Harris, C. Harris, T. Harris, T.D. Harrison, D. Harrison, T.C. Hart, B. Hartnell, S. Hassan, J. Haughney, S. Hawkins, J. Hay, I. Head, J. Henry, M. Hermosin Herrera, D.B. Hettle, J. Hill, G. Hodges, E. Horne, M.M. Hou, C. Houlihan, E. Howe, N. Howell, J. Humphreys, H.E. Humphries, K. Hurley, C. Huson, A. Hyder-Wright, C. Hyams, S. Ikram, A. Ishwarbhai, M. Ivan, P. Iveson, V. Iyer, F. Jackson, J. De Jager, S. Jaumdally, H. Jeffers, N. Jesudason, B. Jones, K. Jones, E. Jones, C. Jones, M.R. Jorge, A. Jose, A. Joshi, E.A.M.S. Júnior, J. Kadziola, R. Kailath, F. Kana, K. Karampatsas, M. Kasanyinga, J. Keen, E.J. Kelly, D.M. Kelly, D. Kelly, S. Kelly, D. Kerr, R. de Á. Kfouri, L. Khan, B. Khozoee, S. Kidd, A. Killen, J. Kinch, P. Kinch, L.D.W. King, T.B. King, L. Kingham, P. Klenerman, F. Knapper, J.C. Knight, D. Knott, S. Koleva, M. Lang, G. Lang, C.W. Larkworthy, J.P.J. Larwood, R. Law, E.M. Lazarus, A. Leach, E.A. Lees, N.-M. Lemm, A. Lessa, S. Leung, Y. Li, A.M. Lias, K. Liatsikos, A. Linder, S. Lipworth, S. Liu, X. Liu, A. Lloyd, S. Lloyd, L. Loew, R. Lopez Ramon, L. Lora, V. Lowthorpe, K. Luz, J.C. MacDonald, G. MacGregor, M. Madhavan, D.O. Mainwaring, E. Makambwa, R. Makinson, M. Malahleha, R. Malamatsho, G. Mallett, K. Mansatta, T. Maoko, K. Mapetla, N.G. Marchevsky, S. Marinou, E. Marlow, G.N. Marques, P. Marriott, R.P. Marshall, J.L. Marshall, F.J. Martins, M. Masenya, M. Masilela, S.K. Masters, M. 
Mathew, H. Matlebjane, K. Matshidiso, O. Mazur, A. Mazzella, H. McCaughan, J. McEwan, J. McGlashan, L. McInroy, Z. McIntyre, D. McLenaghan, N. McRobert, S. McSwiggan, C. Megson, S. Mehdipour, W. Meijs, R.N.Á. Mendonça, A.J. Mentzer, N. Mirtorabi, C. Mitton, S. Mnyakeni, F. Moghaddas, K. Molapo, M. Moloi, M. Moore, M.I. Moraes-Pinto, M. Moran, E. Morey, R. Morgans, S. Morris, S. Morris, H.C. Morris, F. Morselli, G. Morshead, R. Morter, L. Mottal, A. Moultrie, N. Moya, M. Mpelembue, S. Msomi, Y. Mugodi, E. Mukhopadhyay, J. Muller, A. Munro, C. Munro, S. Murphy, P. Mweu, C.H. Myasaki, G. Naik, K. Naker, E. Nastouli, A. Nazir, B. Ndlovu, F. Neffa, C. Njenga, H. Noal, A. Noé, G. Novaes, F.L. Nugent, G. Nunes, K. O'Brien, D. O'Connor, M. Odam, S. Oelofse, B. Oguti, V. Olchawski, N.J. Oldfield, M.G. Oliveira, C. Oliveira, A. Oosthuizen, P. O'Reilly, P. Osborne, D.R.J. Owen, L. Owen, D. Owens, N. Owino, M. Pacurar, B.V.B. Paiva, E.M.F. Palhares, S. Palmer, S. Parkinson, H.M.R.T. Parracho, K. Parsons, D. Patel, B. Patel, F. Patel, K. Patel, M. Patrick-Smith, R.O. Payne, Y. Peng, E.J. Penn, A. Pennington, M.P. Peralta Alvarez, J. Perring, N. Perry, R. Perumal, S. Petkar, T. Philip, D.J. Phillips, J. Phillips, M.K. Phohu, L. Pickup, S. Pieterse, J. Piper, D. Pipini, M. Plank, J. Du Plessis, S. Pollard, J. Pooley, A. Pooran, I. Poulton, C. Powers, F.B. Presa, D.A. Price, V. Price, M. Primeira, P.C. Proud, S. Provstgaard-Morys, S. Pueschel, D. Pulido, S. Quaid, R. Rabara, A. Radford, K. Radia, D. Rajapaska, T. Rajeswaran, A.S.F. Ramos, F. Ramos Lopez, T. Rampling, J. Rand, H. Ratcliffe, T. Rawlinson, D. Rea, B. Rees, J. Reiné, M. Resuello-Dauti, E. Reyes Pabon, C.M. Ribiero, M. Ricamara, A. Richter, N. Ritchie, A.J. Ritchie, A.J. Robbins, H. Roberts, R.E. Robinson, H. Robinson, T.T. Rocchetti, B.P. Rocha, S. Roche, C. Rollier, L. Rose, A.L. Ross Russell, L. Rossouw, S. Royal, I. Rudiansyah, S. Ruiz, S. Saich, C. Sala, J. Sale, A.M. Salman, N. Salvador, S. Salvador, M. Sampaio, A.D. Samson, A. Sanchez-Gonzalez, H. Sanders, K. Sanders, E. Santos, M.F.S. Santos Guerra, I. Satti, J.E. Saunders, C. Saunders, A. Sayed, I. Schim van der Loeff, A.B. Schmid, E. Schofield, G. Screaton, S. Seddiqi, R.R. Segireddy, R. Senger, S. Serrano, R. Shah, I. Shaik, H.E. Sharpe, K. Sharrocks, R. Shaw, A. Shea, A. Shepherd, J.G. Shepherd, F. Shiham, E. Sidhom, S.E. Silk, A.C. da Silva Moraes, G. Silva-Junior, L. Silva-Reyes, A.D. Silveira, M.B.V. Silveira, J. Sinha, D.T. Skelly, D.C. Smith, N. Smith, H.E. Smith, D.J. Smith, C.C. Smith, A. Soares, T. Soares, C. Solórzano, G.L. Sorio, K. Sorley, T. Sosa-Rodriguez, C.M.C.D.L. Souza, B.S.D.F. Souza, A.R. Souza, A.J. Spencer, F. Spina, L. Spoors, L. Stafford, I. Stamford, I. Starinskij, R. Stein, J. Steven, L. Stockdale, L.V. Stockwell, L.H. Strickland, A.C. Stuart, A. Sturdy, N. Sutton, A. Szigeti, A. Tahiri-Alaoui, R. Tanner, C. Taoushanis, A.W. Tarr, K. Taylor, U. Taylor, I.J. Taylor, J. Taylor, R. te Water Naude, Y. Themistocleous, A. Themistocleous, M. Thomas, K. Thomas, T.M. Thomas, A. Thombrayil, F. Thompson, A. Thompson, K. Thompson, A. Thompson, J. Thomson, V. Thornton-Jones, P.J. Tighe, L.A. Tinoco, G. Tiongson, B. Tladinyane, M. Tomasicchio, A. Tomic, S. Tonks, J. Towner, N. Tran, J. Tree, G. Trillana, C. Trinham, R. Trivett, A. Truby, B.L. Tsheko, A. Turabi, R. Turner, C. Turner, M. Ulaszewska, B.R. Underwood, R. Varughese, D. Verbart, M. Verheul, I. Vichos, T. Vieira, C.S. Waddington, L. Walker, E. Wallis, M. Wand, D. Warbick, T. Wardell, G. Warimwe, S.C. Warren, B. Watkins, E. Watson, S. Webb, A. Webb-Bridges, A. Webster, J. Welch, J. Wells, A. West, C. White, R. White, P. Williams, R.L. Williams, R. Winslow, M. Woodyer, A.T. Worth, D. Wright, M. Wroblewska, A. Yao, R. Zimmer, D. Zizi, P. Zuidewind, Safety and efficacy of the ChAdOx1 nCoV-19 vaccine (AZD1222) against SARS-CoV-2: an interim analysis of four randomised controlled trials in Brazil, South Africa, and the UK, The Lancet. 397 (2021) 99-111. https://doi.org/10.1016/S0140-6736(20)32661-1.

[2] L.R. Baden, H.M. El Sahly, B. Essink, K. Kotloff, S. Frey, R. Novak, D. Diemert, S.A. Spector, N. Rouphael, C.B. Creech, J. McGettigan, S. Khetan, N. Segall, J. Solis, A. Brosz, C. Fierro, H. Schwartz, K. Neuzil, L. Corey, P. Gilbert, H. Janes, D. Follmann, M. Marovich, J. Mascola, L. Polakowski, J. Ledgerwood, B.S. Graham, H. Bennett, R. Pajon, C. Knightly, B. Leav, W. Deng, H. Zhou, S. Han, M. Ivarsson, J. Miller, T. Zaks, Efficacy and Safety of the mRNA-1273 SARSCoV-2 Vaccine, N Engl J Med. 384 (2021) 403-416. https://doi.org/10.1056/NEJMoa2035389.

[3] E.J. Haas, F.J. Angulo, J.M. McLaughlin, E. Anis, S.R. Singer, F. Khan, N. Brooks, M. Smaja, G. Mircus, K. Pan, J. Southern, D.L. Swerdlow, L. Jodar, Y. Levy, S. Alroy-Preis, Impact and 
effectiveness of mRNA BNT162b2 vaccine against SARS-CoV-2 infections and COVID-19 cases, hospitalisations, and deaths following a nationwide vaccination campaign in Israel: an observational study using national surveillance data, The Lancet. 397 (2021) 1819-1829. https://doi.org/10.1016/S0140-6736(21)00947-8.

[4] F.P. Polack, S.J. Thomas, N. Kitchin, J. Absalon, A. Gurtman, S. Lockhart, J.L. Perez, G. Pérez Marc, E.D. Moreira, C. Zerbini, R. Bailey, K.A. Swanson, S. Roychoudhury, K. Koury, P. Li, W.V. Kalina, D. Cooper, R.W. Frenck, L.L. Hammitt, Ö. Türeci, H. Nell, A. Schaefer, S. Ünal, D.B. Tresnan, S. Mather, P.R. Dormitzer, U. Şahin, K.U. Jansen, W.C. Gruber, Safety and Efficacy of the BNT162b2 mRNA Covid-19 Vaccine, N Engl J Med. 383 (2020) 2603-2615. https://doi.org/10.1056/NEJMoa2034577.

[5] A. Asghari, M. Naseri, H. Safari, E. Saboory, N. Parsamanesh, The Novel Insight of SARS-CoV2 Molecular Biology and Pathogenesis and Therapeutic Options, DNA and Cell Biology. 39 (2020) 1741-1753. https://doi.org/10.1089/dna.2020.5703.

[6] M. Cevik, K. Kuppalli, J. Kindrachuk, M. Peiris, Virology, transmission, and pathogenesis of SARS-CoV-2, BMJ. (2020) m3862. https://doi.org/10.1136/bmj.m3862.

[7] N. Redondo, S. Zaldívar-López, J.J. Garrido, M. Montoya, SARS-CoV-2 Accessory Proteins in Viral Pathogenesis: Knowns and Unknowns, Front. Immunol. 12 (2021) 708264. https://doi.org/10.3389/fimmu.2021.708264.

[8] J.A. Silvas, D.M. Vasquez, J.-G. Park, K. Chiem, A. Allué-Guardia, A. Garcia-Vilanova, R.N. Platt, L. Miorin, T. Kehrer, A. Cupic, A.S. Gonzalez-Reiche, H. van Bakel, A. García-Sastre, T. Anderson, J.B. Torrelles, C. Ye, L. Martinez-Sobrido, Contribution of SARS-CoV-2 Accessory Proteins to Viral Pathogenicity in K18 Human ACE2 Transgenic Mice, J Virol. 95 (2021) e0040221. https://doi.org/10.1128/JVI.00402-21.

[9] T. Koyama, D. Platt, L. Parida, Variant analysis of SARS-CoV-2 genomes, Bull. World Health Organ. 98 (2020) 495-504. https://doi.org/10.2471/BLT.20.253591.

[10] M. Sarkar, S. Saha, Structural insight into the role of novel SARS-CoV-2 E protein: A potential target for vaccine development and other therapeutic strategies, PLoS One. 15 (2020) e0237300. https://doi.org/10.1371/journal.pone.0237300.

[11] L. Guruprasad, Human SARS CoV -2 spike protein mutations, Proteins. 89 (2021) 569-576. https://doi.org/10.1002/prot.26042.

[12] Center for Disease Control and Prevention, Science Brief: COVID-19 Vaccines and Vaccination, 2021. (n.d.). https://www.cdc.gov/coronavirus/2019-ncov/science/science-briefs/fully-vaccinatedpeople.html.

[13] J.L. Nieva, V. Madan, L. Carrasco, Viroporins: structure and biological functions, Nat. Rev. Microbiol. 10 (2012) 563-574. https://doi.org/10.1038/nrmicro2820.

[14] S. Li, L. Yuan, G. Dai, R.A. Chen, D.X. Liu, T.S. Fung, Regulation of the ER Stress Response by the Ion Channel Activity of the Infectious Bronchitis Coronavirus Envelope Protein Modulates Virion Release, Apoptosis, Viral Fitness, and Pathogenesis, Front. Microbiol. 10 (2020) 3022. https://doi.org/10.3389/fmicb.2019.03022.

[15] J. Nieto-Torres, C. Verdiá-Báguena, C. Castaño-Rodriguez, V. Aguilella, L. Enjuanes, Relevance of Viroporin Ion Channel Activity on Viral Replication and Pathogenesis, Viruses. 7 (2015) 3552-3573. https://doi.org/10.3390/v7072786.

[16] V.S. Mandala, M.J. McKay, A.A. Shcherbakov, A.J. Dregni, A. Kolocouris, M. Hong, Structure and drug binding of the SARS-CoV-2 envelope protein transmembrane domain in lipid bilayers, Nat Struct Mol Biol. 27 (2020) 1202-1208. https://doi.org/10.1038/s41594-020-00536-8.

[17] G. Mariano, R.J. Farthing, S.L.M. Lale-Farjat, J.R.C. Bergeron, Structural Characterization of SARS-CoV-2: Where We Are, and Where We Need to Be, Front. Mol. Biosci. 7 (2020) 605236. https://doi.org/10.3389/fmolb.2020.605236.

[18] P.P. Singh Tomar, I.T. Arkin, SARS-CoV-2 E protein is a potential ion channel that can be inhibited by Gliclazide and Memantine, Biochemical and Biophysical Research Communications. 530 (2020) 10-14. https://doi.org/10.1016/j.bbrc.2020.05.206. 
[19] D.M. Kern, B. Sorum, S.S. Mali, C.M. Hoel, S. Sridharan, J.P. Remis, D.B. Toso, A. Kotecha, D.M. Bautista, S.G. Brohawn, Cryo-EM structure of SARS-CoV-2 ORF3a in lipid nanodiscs, Nat Struct Mol Biol. 28 (2021) 573-582. https://doi.org/10.1038/s41594-021-00619-0.

[20] P. Fong, SARS-CoV-2: pushing the E(nvelope), J Physiol. 599 (2021) 2785-2786. https://doi.org/10.1113/JP281601.

[21] D. Schoeman, B.C. Fielding, Coronavirus envelope protein: current knowledge, Virol. J. 16 (2019) 69. https://doi.org/10.1186/s12985-019-1182-0.

[22] J. Zhang, R. Cruz-cosme, M.-W. Zhuang, D. Liu, Y. Liu, S. Teng, P.-H. Wang, Q. Tang, A systemic and molecular study of subcellular localization of SARS-CoV-2 proteins, Sig Transduct Target Ther. 5 (2020) 269. https://doi.org/10.1038/s41392-020-00372-8.

[23] G. Miao, H. Zhao, Y. Li, M. Ji, Y. Chen, Y. Shi, Y. Bi, P. Wang, H. Zhang, ORF3a of the COVID19 virus SARS-CoV-2 blocks HOPS complex-mediated assembly of the SNARE complex required for autolysosome formation, Developmental Cell. 56 (2021) 427-442.e5. https://doi.org/10.1016/j.devcel.2020.12.010.

[24] R.R. Gonzales, C.E. Machamer, The SARS CoV-1 3a protein disrupts Golgi complex morphology and cargo trafficking, Cell Biology, 2021. https://doi.org/10.1101/2021.04.19.440492.

[25] E.C. Freundt, L. Yu, C.S. Goldsmith, S. Welsh, A. Cheng, B. Yount, W. Liu, M.B. Frieman, U.J. Buchholz, G.R. Screaton, J. Lippincott-Schwartz, S.R. Zaki, X.-N. Xu, R.S. Baric, K. Subbarao, M.J. Lenardo, The Open Reading Frame 3a Protein of Severe Acute Respiratory SyndromeAssociated Coronavirus Promotes Membrane Rearrangement and Cell Death, J Virol. 84 (2010) 1097-1109. https://doi.org/10.1128/JVI.01662-09.

[26] Y. Lim, Y. Ng, J. Tam, D. Liu, Human Coronaviruses: A Review of Virus-Host Interactions, Diseases. 4 (2016) 26. https://doi.org/10.3390/diseases4030026.

[27] D. Cabrera-Garcia, R. Bekdash, G.W. Abbott, M. Yazawa, N.L. Harrison, The envelope protein of SARS-CoV-2 increases intra-Golgi pH and forms a cation channel that is regulated by $\mathrm{pH}, \mathrm{J}$ Physiol. 599 (2021) 2851-2868. https://doi.org/10.1113/JP281037.

[28] E. Fan, J.R. Beitler, L. Brochard, C.S. Calfee, N.D. Ferguson, A.S. Slutsky, D. Brodie, COVID19-associated acute respiratory distress syndrome: is a different approach to management warranted?, The Lancet Respiratory Medicine. 8 (2020) 816-821. https://doi.org/10.1016/S2213-2600(20)30304-0.

[29] G.K. Azad, P.K. Khan, Variations in Orf3a protein of SARS-CoV-2 alter its structure and function, Biochemistry and Biophysics Reports. 26 (2021) 100933. https://doi.org/10.1016/j.bbrep.2021.100933.

[30] H. Ode, M. Nakashima, S. Kitamura, W. Sugiura, H. Sato, Molecular dynamics simulation in virus research, Front. Microbio. 3 (2012). https://doi.org/10.3389/fmicb.2012.00258.

[31] F. Sievers, A. Wilm, D. Dineen, T.J. Gibson, K. Karplus, W. Li, R. Lopez, H. McWilliam, M. Remmert, J. Söding, J.D. Thompson, D.G. Higgins, Fast, scalable generation of high-quality protein multiple sequence alignments using Clustal Omega, Mol Syst Biol. 7 (2011) 539. https://doi.org/10.1038/msb.2011.75.

[32] S. Kumar, S.R. Gadagkar, Disparity index: a simple statistic to measure and test the homogeneity of substitution patterns between molecular sequences, Genetics. 158 (2001) 1321-1327.

[33] S. Kumar, G. Stecher, M. Li, C. Knyaz, K. Tamura, MEGA X: Molecular Evolutionary Genetics Analysis across Computing Platforms, Molecular Biology and Evolution. 35 (2018) 1547-1549. https://doi.org/10.1093/molbev/msy096.

[34] Zuckerkandl, E, Pauling L, Evolutionary divergence and convergence in proteins, Academic Press, New York, 1965.

[35] W. Surya, Y. Li, J. Torres, Structural model of the SARS coronavirus E channel in LMPG micelles, Biochim Biophys Acta Biomembr. 1860 (2018) 1309-1317. https://doi.org/10.1016/j.bbamem.2018.02.017. 
[36] A.D. Baxevanis, Current protocols in bioinformatics, John Wiley and Sons, New York, 2004. http://onlinelibrary.wiley.com/book/10.1002/0471250953 (accessed September 26, 2021).

[37] A. Waterhouse, M. Bertoni, S. Bienert, G. Studer, G. Tauriello, R. Gumienny, F.T. Heer, T.A.P. de Beer, C. Rempfer, L. Bordoli, R. Lepore, T. Schwede, SWISS-MODEL: homology modelling of protein structures and complexes, Nucleic Acids Res. 46 (2018) W296-W303. https://doi.org/10.1093/nar/gky427.

[38] J. Ko, H. Park, L. Heo, C. Seok, GalaxyWEB server for protein structure prediction and refinement, Nucleic Acids Res. 40 (2012) W294-297. https://doi.org/10.1093/nar/gks493.

[39] C.J. Williams, J.J. Headd, N.W. Moriarty, M.G. Prisant, L.L. Videau, L.N. Deis, V. Verma, D.A. Keedy, B.J. Hintze, V.B. Chen, S. Jain, S.M. Lewis, W.B. Arendall, J. Snoeyink, P.D. Adams, S.C. Lovell, J.S. Richardson, D.C. Richardson, MolProbity: More and better reference data for improved all-atom structure validation, Protein Sci. 27 (2018) 293-315. https://doi.org/10.1002/pro.3330.

[40] I.W. Davis, A. Leaver-Fay, V.B. Chen, J.N. Block, G.J. Kapral, X. Wang, L.W. Murray, W.B. Arendall, J. Snoeyink, J.S. Richardson, D.C. Richardson, MolProbity: all-atom contacts and structure validation for proteins and nucleic acids, Nucleic Acids Res. 35 (2007) W375-383. https://doi.org/10.1093/nar/gkm216.

[41] S. Jo, T. Kim, W. Im, Automated builder and database of protein/membrane complexes for molecular dynamics simulations, PLoS ONE. 2 (2007) e880. https://doi.org/10.1371/journal.pone.0000880.

[42] E.L. Wu, X. Cheng, S. Jo, H. Rui, K.C. Song, E.M. Dávila-Contreras, Y. Qi, J. Lee, V. MonjeGalvan, R.M. Venable, J.B. Klauda, W. Im, CHARMM-GUI Membrane Builder toward realistic biological membrane simulations, J Comput Chem. 35 (2014) 1997-2004. https://doi.org/10.1002/jcc.23702.

[43] W.L. Jorgensen, J. Chandrasekhar, J.D. Madura, R.W. Impey, M.L. Klein, Comparison of simple potential functions for simulating liquid water, The Journal of Chemical Physics. 79 (1983) 926935. https://doi.org/10.1063/1.445869.

[44] R.B. Best, X. Zhu, J. Shim, P.E.M. Lopes, J. Mittal, M. Feig, A.D. Mackerell, Optimization of the additive CHARMM all-atom protein force field targeting improved sampling of the backbone $\varphi, \psi$ and side-chain X(1) and X(2) dihedral angles, J Chem Theory Comput. 8 (2012) 3257-3273. https://doi.org/10.1021/ct300400x.

[45] J.B. Klauda, R.M. Venable, J.A. Freites, J.W. O'Connor, D.J. Tobias, C. Mondragon-Ramirez, I. Vorobyov, A.D. MacKerell, R.W. Pastor, Update of the CHARMM all-atom additive force field for lipids: validation on six lipid types, J Phys Chem B. 114 (2010) 7830-7843. https://doi.org/10.1021/jp101759q.

[46] J.C. Phillips, R. Braun, W. Wang, J. Gumbart, E. Tajkhorshid, E. Villa, C. Chipot, R.D. Skeel, L. Kalé, K. Schulten, Scalable molecular dynamics with NAMD, J Comput Chem. 26 (2005) 17811802. https://doi.org/10.1002/jcc.20289.

[47] J.R. Silva, H. Pan, D. Wu, A. Nekouzadeh, K.F. Decker, J. Cui, N.A. Baker, D. Sept, Y. Rudy, A multiscale model linking ion-channel molecular dynamics and electrostatics to the cardiac action potential, Proc Natl Acad Sci U S A. 106 (2009) 11102-11106. https://doi.org/10.1073/pnas.0904505106.

[48] J.-P. Ryckaert, G. Ciccotti, H.J.C. Berendsen, Numerical integration of the cartesian equations of motion of a system with constraints: molecular dynamics of $n$-alkanes, Journal of Computational Physics. 23 (1977) 327-341. https://doi.org/10.1016/0021-9991(77)90098-5.

[49] S.E. Feller, Y. Zhang, R.W. Pastor, B.R. Brooks, Constant pressure molecular dynamics simulation: The Langevin piston method, The Journal of Chemical Physics. 103 (1995) 46134621. https://doi.org/10.1063/1.470648.

[50] T. Darden, D. York, L. Pedersen, Particle mesh Ewald: An $N \cdot \log (N)$ method for Ewald sums in large systems, The Journal of Chemical Physics. 98 (1993) 10089-10092. https://doi.org/10.1063/1.464397. 
[51] W. Humphrey, A. Dalke, K. Schulten, VMD: Visual molecular dynamics, Journal of Molecular Graphics. 14 (1996) 33-38. https://doi.org/10.1016/0263-7855(96)00018-5.

[52] E.F. Pettersen, T.D. Goddard, C.C. Huang, G.S. Couch, D.M. Greenblatt, E.C. Meng, T.E. Ferrin, UCSF Chimera--a visualization system for exploratory research and analysis, J Comput Chem. 25 (2004) 1605-1612. https://doi.org/10.1002/jcc.20084.

[53] H. Katsura, V. Sontake, A. Tata, Y. Kobayashi, C.E. Edwards, B.E. Heaton, A. Konkimalla, T. Asakura, Y. Mikami, E.J. Fritch, P.J. Lee, N.S. Heaton, R.C. Boucher, S.H. Randell, R.S. Baric, P.R. Tata, Human Lung Stem Cell-Based Alveolospheres Provide Insights into SARS-CoV-2Mediated Interferon Responses and Pneumocyte Dysfunction, Cell Stem Cell. 27 (2020) 890904.e8. https://doi.org/10.1016/j.stem.2020.10.005.

[54] M.I. Love, W. Huber, S. Anders, Moderated estimation of fold change and dispersion for RNAseq data with DESeq2, Genome Biol. 15 (2014) 550. https://doi.org/10.1186/s13059-014-05508.

[55] Y. Zhou, B. Zhou, L. Pache, M. Chang, A.H. Khodabakhshi, O. Tanaseichuk, C. Benner, S.K. Chanda, Metascape provides a biologist-oriented resource for the analysis of systems-level datasets, Nat Commun. 10 (2019) 1523. https://doi.org/10.1038/s41467-019-09234-6.

[56] F. Lang, M. Föller, Regulation of ion channels and transporters by AMP-activated kinase (AMPK), Channels. 8 (2014) 20-28. https://doi.org/10.4161/chan.27423.

[57] M.E. Gonzalez, L. Carrasco, Viroporins, FEBS Letters. 552 (2003) 28-34. https://doi.org/10.1016/S0014-5793(03)00780-4.

[58] C. McClenaghan, A. Hanson, S.-J. Lee, C.G. Nichols, Coronavirus Proteins as Ion Channels: Current and Potential Research, Front. Immunol. 11 (2020) 573339. https://doi.org/10.3389/fimmu.2020.573339.

[59] B. Bakhshandeh, Z. Jahanafrooz, A. Abbasi, M.B. Goli, M. Sadeghi, M.S. Mottaqi, M. Zamani, Mutations in SARS-CoV-2; Consequences in structure, function, and pathogenicity of the virus, Microb Pathog. 154 (2021) 104831. https://doi.org/10.1016/j.micpath.2021.104831.

[60] M.-Y. Wang, R. Zhao, L.-J. Gao, X.-F. Gao, D.-P. Wang, J.-M. Cao, SARS-CoV-2: Structure, Biology, and Structure-Based Therapeutics Development, Front. Cell. Infect. Microbiol. 10 (2020) 587269. https://doi.org/10.3389/fcimb.2020.587269.

[61] J. Lan, J. Ge, J. Yu, S. Shan, H. Zhou, S. Fan, Q. Zhang, X. Shi, Q. Wang, L. Zhang, X. Wang, Structure of the SARS-CoV-2 spike receptor-binding domain bound to the ACE2 receptor, Nature. 581 (2020) 215-220. https://doi.org/10.1038/s41586-020-2180-5.

[62] R. Yan, Y. Zhang, Y. Li, L. Xia, Y. Guo, Q. Zhou, Structural basis for the recognition of SARSCoV-2 by full-length human ACE2, Science. 367 (2020) 1444-1448. https://doi.org/10.1126/science.abb2762.

[63] Y. Gao, L. Yan, Y. Huang, F. Liu, Y. Zhao, L. Cao, T. Wang, Q. Sun, Z. Ming, L. Zhang, J. Ge, L. Zheng, Y. Zhang, H. Wang, Y. Zhu, C. Zhu, T. Hu, T. Hua, B. Zhang, X. Yang, J. Li, H. Yang, Z. Liu, W. Xu, L.W. Guddat, Q. Wang, Z. Lou, Z. Rao, Structure of the RNA-dependent RNA polymerase from COVID-19 virus, Science. 368 (2020) 779-782. https://doi.org/10.1126/science.abb7498.

[64] Z. Jin, X. Du, Y. Xu, Y. Deng, M. Liu, Y. Zhao, B. Zhang, X. Li, L. Zhang, C. Peng, Y. Duan, J. Yu, L. Wang, K. Yang, F. Liu, R. Jiang, X. Yang, T. You, X. Liu, X. Yang, F. Bai, H. Liu, X. Liu, L.W. Guddat, W. Xu, G. Xiao, C. Qin, Z. Shi, H. Jiang, Z. Rao, H. Yang, Structure of Mpro from SARS-CoV-2 and discovery of its inhibitors, Nature. 582 (2020) 289-293. https://doi.org/10.1038/s41586-020-2223-y.

[65] R. Manzoor, M. Igarashi, A. Takada, Influenza A Virus M2 Protein: Roles from Ingress to Egress, IJMS. 18 (2017) 2649. https://doi.org/10.3390/ijms18122649.

[66] S. Jones, Death by viroporin, Nat Rev Microbiol. 5 (2007) 907-907. https://doi.org/10.1038/nrmicro1801.

[67] N. Zamzami, G. Kroemer, The mitochondrion in apoptosis: how Pandora's box opens, Nat Rev Mol Cell Biol. 2 (2001) 67-71. https://doi.org/10.1038/35048073. 
[68] N.S. Farag, U. Breitinger, M. El-Azizi, H.-G. Breitinger, The $p 7$ viroporin of the hepatitis $C$ virus contributes to liver inflammation by stimulating production of Interleukin-1 $\beta$, Biochimica et Biophysica Acta (BBA) - Molecular Basis of Disease. 1863 (2017) 712-720. https://doi.org/10.1016/j.bbadis.2016.12.006.

[69] J.L. Nieto-Torres, C. Verdiá-Báguena, J.M. Jimenez-Guardeño, J.A. Regla-Nava, C. CastañoRodriguez, R. Fernandez-Delgado, J. Torres, V.M. Aguilella, L. Enjuanes, Severe acute respiratory syndrome coronavirus E protein transports calcium ions and activates the NLRP3 inflammasome, Virology. 485 (2015) 330-339. https://doi.org/10.1016/j.virol.2015.08.010.

[70] I.-Y. Chen, M. Moriyama, M.-F. Chang, T. Ichinohe, Severe Acute Respiratory Syndrome Coronavirus Viroporin 3a Activates the NLRP3 Inflammasome, Front. Microbiol. 10 (2019) 50. https://doi.org/10.3389/fmicb.2019.00050.

[71] R. Bartoszewski, S. Matalon, J.F. Collawn, lon channels of the lung and their role in disease pathogenesis, American Journal of Physiology-Lung Cellular and Molecular Physiology. 313 (2017) L859-L872. https://doi.org/10.1152/ajplung.00285.2017.

[72] X. Li, X. Ma, Acute respiratory failure in COVID-19: is it "typical" ARDS?, Crit Care. 24 (2020) 198. https://doi.org/10.1186/s13054-020-02911-9.

[73] M.A. Torres Acosta, B.D. Singer, Pathogenesis of COVID-19-induced ARDS: implications for an ageing population, Eur Respir J. 56 (2020) 2002049. https://doi.org/10.1183/13993003.020492020.

[74] M. Shahbazi, P. Amri Maleh, M. Bagherzadeh, Z. Moulana, M. Sepidarkish, M. Rezanejad, M. Mirzakhani, S. Ebrahimpour, H. Ghorbani, Z. Ahmadnia, M. Javanian, M. bayani, M. Mohammadnia-Afrouzi, Linkage of Lambda Interferons in Protection Against Severe COVID-19, Journal of Interferon \& Cytokine Research. 41 (2021) 149-152. https://doi.org/10.1089/jir.2020.0187.

[75] A. Hariharan, A.R. Hakeem, S. Radhakrishnan, M.S. Reddy, M. Rela, The Role and Therapeutic Potential of NF-kappa-B Pathway in Severe COVID-19 Patients, Inflammopharmacol. 29 (2021) 91-100. https://doi.org/10.1007/s10787-020-00773-9.

[76] E.M. Wilfong, R. Croze, X. Fang, M. Schwede, E. Niemi, G.Y. López, J.-W. Lee, M.C. Nakamura, M.A. Matthay, Proinflammatory cytokines and ARDS pulmonary edema fluid induce CD40 on human mesenchymal stromal cells-A potential mechanism for immune modulation, PLoS ONE. 15 (2020) e0240319. https://doi.org/10.1371/journal.pone.0240319.

[77] Q. Notz, M. Schmalzing, F. Wedekink, T. Schlesinger, M. Gernert, J. Herrmann, L. Sorger, D. Weismann, B. Schmid, M. Sitter, N. Schlegel, P. Kranke, J. Wischhusen, P. Meybohm, C. Lotz, Pro- and Anti-Inflammatory Responses in Severe COVID-19-Induced Acute Respiratory Distress Syndrome—An Observational Pilot Study, Front. Immunol. 11 (2020) 581338. https://doi.org/10.3389/fimmu.2020.581338.

[78] V.J. Costela-Ruiz, R. Illescas-Montes, J.M. Puerta-Puerta, C. Ruiz, L. Melguizo-Rodríguez, SARS-CoV-2 infection: The role of cytokines in COVID-19 disease, Cytokine \& Growth Factor Reviews. 54 (2020) 62-75. https://doi.org/10.1016/j.cytogfr.2020.06.001.

[79] S. Lin, H. Wu, C. Wang, Z. Xiao, F. Xu, Regulatory T Cells and Acute Lung Injury: Cytokines, Uncontrolled Inflammation, and Therapeutic Implications, Front. Immunol. 9 (2018) 1545. https://doi.org/10.3389/fimmu.2018.01545.

[80] M.L. DeDiego, J.L. Nieto-Torres, J.A. Regla-Nava, J.M. Jimenez-Guardeño, R. FernandezDelgado, C. Fett, C. Castaño-Rodriguez, S. Perlman, L. Enjuanes, Inhibition of NF-KB-mediated inflammation in severe acute respiratory syndrome coronavirus-infected mice increases survival, J. Virol. 88 (2014) 913-924. https://doi.org/10.1128/JVI.02576-13.

[81] N. Kanzawa, K. Nishigaki, T. Hayashi, Y. Ishii, S. Furukawa, A. Niiro, F. Yasui, M. Kohara, K. Morita, K. Matsushima, M.Q. Le, T. Masuda, M. Kannagi, Augmentation of chemokine production by severe acute respiratory syndrome coronavirus $3 \mathrm{a} / \mathrm{X} 1$ and $7 \mathrm{a} / \mathrm{X} 4$ proteins through NF-KB activation, FEBS Letters. 580 (2006) 6807-6812. https://doi.org/10.1016/j.febslet.2006.11.046. 
[82] N. Kelley, D. Jeltema, Y. Duan, Y. He, The NLRP3 Inflammasome: An Overview of Mechanisms of Activation and Regulation, IJMS. 20 (2019) 3328. https://doi.org/10.3390/ijms20133328.

[83] M.N. Andersen, H.B. Rasmussen, AMPK: A regulator of ion channels, Communicative \& Integrative Biology. 5 (2012) 480-484. https://doi.org/10.4161/cib.21200.

[84] V. Barrese, J.B. Stott, H.B. Figueiredo, A.A. Aubdool, A.J. Hobbs, T.A. Jepps, A.J. McNeish, I.A. Greenwood, Angiotensin II Promotes $\mathrm{K}_{\mathrm{v}} 7.4$ Channels Degradation Through Reduced Interaction With HSP90 (Heat Shock Protein 90), Hypertension. 71 (2018) 1091-1100. https://doi.org/10.1161/HYPERTENSIONAHA.118.11116.

[85] T. Murakami, J. Ockinger, J. Yu, V. Byles, A. McColl, A.M. Hofer, T. Horng, Critical role for calcium mobilization in activation of the NLRP3 inflammasome, Proceedings of the National Academy of Sciences. 109 (2012) 11282-11287. https://doi.org/10.1073/pnas.1117765109. 
bioRxiv preprint doi: https://doi.org/10.1101/2021.09.26.461873; this version posted September 26, 2021. The copyright holder for this preprint (which was not certified by peer review) is the author/funder. All rights reserved. No reuse allowed without permission.

\section{Figure \& Table Legends}

\section{Table 1.}

Lipid composition of different membrane components of intracellular compartments (endosome, golgi and ERGIC).

Fig. 1. 
A. Sequence alignment of CoV Orf3a proteins performed by Clustal Omega after a BLASTp search against human SARS-CoV-2 Orf3a protein (Accession number: QRN50954). The conserved sequences, quality of sequence alignment, and consensus sequence are shown below.

B. Evolutionary tree representation of selected Orf3a sequences from different species (bats, pangolin, civet, humans-CoV-1, humans-CoV-2). The distance is shown at the top and is calculated using the neighbour-joining method. The colors indicate differently clustered Orf3a sequences according to their species.

C. Lower triangular heat map representation of the pairwise distance computed from the sequence alignment for selected Orf3a proteins. Heatmap scale: 04.5.

D. Lower triangular heat map representation of the disparity index computed from the sequence alignment for Orf3a protein sequences obtained after a BLASTp search. Heatmap scale: 0-5.

Fig. 2.

A. Insertion and equilibration of truncated Orf3a (40-125) from SARS-CoV-2 in a membrane system mimicking the endosomal compartment of a generalized human cell. The membrane is not shown in the figure to ease the visualization of the molecular machine. The upper subunit channel has been pointed out using a dotted circle.

B. Movement of water molecules through the upper subunit channel at different time points (i) 0 ns (ii) 0.5 ns (iii) 1 ns (iv) 1.5 ns (v) 2 ns (Supplementary Movie 1)

C. Insertion and equilibration of truncated Orf3a (40-125) from SARS-CoV-2 in a membrane system mimicking the endosomal compartment of a generalized human cell. The membrane is not shown in the figure to ease the visualization of the molecular machine. The inter-subunit channel has been pointed out using a dotted circle.

D. Movement of water molecules through the inne-rsubunit channel at different time points (i) 0 ns (ii) 0.5 ns (iii) 1 ns (iv) 1.5 ns (v) 2 ns (Supplementary Movie 1) 
E. Line plot showing the dynamics in the number of hydrogen bonds in the protein-membrane system as a function of time steps for $5 \mathrm{~ns}$ where each time step is $0.1 \mathrm{~ns}$.

F. Line plot showing the RMSD of the protein-membrane complex and its change over a course of 5 ns where each time step is $0.1 \mathrm{~ns}$.

G. Line plot showing the total energy $(\mathrm{kcal} / \mathrm{mol})$ of the system in $5 \mathrm{~ns}$ of simulation with each 5000 steps $=1$ ps.

$H$. Matrix representation showing the RMSF of individual residues of the protein over the time span of $5 \mathrm{~ns}$ where each time step is $0.1 \mathrm{~ns}$.

Fig. 3.

A. Insertion and equilibration of truncated Orf3a (40-125) from SARS-CoV-1 (homology modeled from the Cryo-EM structure of its SARS-CoV-2 counterpart) in a membrane system mimicking the Golgi apparatus of generalized human cell. The membrane is not shown in the figure to ease the visualization of the molecular machine. The upper subunit channel has been pointed out using a dotted circle.

B. Movement of water molecules through the upper subunit channel at different time points (i) 0 ns (ii) 0.5 ns (iii) 1 ns (iv) 1.5 ns (v) 2 ns (Supplementary Movie 2)

C. Insertion and equilibration of truncated Orf3a (40-125) from SARS-CoV-1 in a membrane system mimicking the Golgi apparatus of generalized human cells. The membrane is not shown in the figure to ease the visualization of the molecular machine. The inter-subunit channel has been pointed out using a dotted circle.

D. Movement of water molecules through the inne-rsubunit channel at different time points (i) 0 ns (ii) 0.5 ns (iii) 1 ns (iv) 1.5 ns (v) 2 ns (Supplementary Movie 2)

E. Line plot showing the dynamics in the number of hydrogen bonds in the protein-membrane system as a function of time steps for 5 ns where each time step is $0.1 \mathrm{~ns}$.

F. Line plot showing the RMSD of the protein-membrane complex and its change over a course of $5 \mathrm{~ns}$ where each time step is $0.1 \mathrm{~ns}$. 
G. Line plot showing the total energy $(\mathrm{kcal} / \mathrm{mol})$ of the system in 5 ns of simulation with each 5000 steps $=1$ ps.

$H$. Matrix representation showing the RMSF of individual residues of the protein over the time span of $5 \mathrm{~ns}$ where each time step is $0.1 \mathrm{~ns}$.

Fig. 4.

A. Sequential analysis of the Orf $3 a$ from SARS-CoV-1 and SARS-CoV-2 showing the possible mutations in several regions of the protein.

B. Structural superimposition of Orf3a from SARS-CoV-1 (cyan) and SARS-CoV2 (green) showing the pore-lining residues of the inter-subunit channel in the red box.

C. Magnified image of the red box showing the pore-lining residues of the intersubunit channel of Orf3a from SARS-CoV-1 (blue) and SARS-CoV-2 (magenta).

D. Inter-subunit channel of Orf3a from SARS-CoV-1 with the blue arrow showing the surface of the pore-lining residues and water dynamics (Supplementary Movie 2).

E. Inter-subunit channel of Orf3a from SARS-CoV-2 with the blue arrow showing the surface of the pore-lining residues and water dynamics (Supplementary Movie 1).

F. CastP analysis of the central core of Orf3a from SARS-CoV-1 with the blue arrow showing the absence of any pocket near the inter-subunit channel.

G. CastP analysis of the central core of Orf3a from SARS-CoV-2 with the blue arrow showing the presence of the pocket near the inter-subunit channel.

$\mathrm{H}$. Violin plot showing significant differences in the total SASA of the inter-subunit channel lining residues of Orf3a from SARS-CoV-1 and SARS-CoV-2.

I. Line plots showing the RMSF and total SASA of the pore-lining residues of Orf3a from SARS-CoV-1 for 2 ns simulation time with each time step=0.1 ns.

J. Line plots showing the RMSF and total SASA of the pore-lining residues of Orf3a from SARS-CoV-2 for 2 ns simulation time with each time step=0.1 ns.

K. Violin plot showing significant differences in the total energy $(\mathrm{kcal} / \mathrm{mol})$ of Orf3a (40-125)- membrane complex from SARS-CoV-1 and SARS-CoV-2. 
Fig. 5.

A. Insertion and equilibration of PO model of Envelope (E) protein (8-40) of SARS-CoV-2 in a membrane system mimicking the ERGIC of human cells. The membrane is not shown in the figure to ease the visualization of the molecular machine.

B. Movement of water molecules through the central pentameric channel of the TM region of the $E$ protein at different time points (i) 0 ns (ii) 0.5 ns (iii) 1 ns (iv) $1.1 \mathrm{~ns}$ (v) $1.2 \mathrm{~ns}$ (vi) $1.3 \mathrm{~ns}$ (vii) $1.4 \mathrm{~ns}$ (viii) $1.5 \mathrm{~ns}$ (ix) 2 ns (Supplementary Movie 3)

C. Line plot showing the dynamics in the number of hydrogen bonds in the protein-membrane system as a function of time steps for 5 ns where each time step is $0.1 \mathrm{~ns}$.

D. Line plot showing the RMSD of the protein-membrane complex and its change over a course of $5 \mathrm{~ns}$ where each time step is $0.1 \mathrm{~ns}$.

E. Line plot showing the total energy $(\mathrm{kcal} / \mathrm{mol})$ of the system in $5 \mathrm{~ns}$ of simulation with each 5000 steps $=1$ ps.

F. Matrix representation showing the RMSF of individual residues of the protein over the time span of $5 \mathrm{~ns}$ where each time step is $0.1 \mathrm{~ns}$.

Fig. 6.

A. Insertion and equilibration of NS model of Envelope protein (8-40) of SARSCoV-2 in a membrane system mimicking the ERGIC of human cells. The membrane is not shown in the figure to ease the visualization of the molecular machine.

B. Movement of water molecules through the central pentameric channel of the TM region of $E$ protein at different time points (i) 0 ns (ii) 0.5 ns (iii) 1 ns (iv) 1.5 ns (v) 2 ns (Supplementary Movie 4)

C. Line plot showing the comparison of RMSD between the NS model and PO model of Envelope protein inserted in similar membrane mimic for $5 \mathrm{~ns}$. The proposed dewetted state (NS model) and the wetted state (PO model) are shown in red and blue respectively.

D. Line plot showing the comparison of the total energy profile between the NS and $\mathrm{PO}$ model of $\mathrm{E}$ protein-membrane systems for $5 \mathrm{~ns}$. The proposed 
dewetted state (NS model) and the wetted state (PO model) are shown in red and blue respectively.

E. Comparison of the cumulative distribution of the total energy profiles between the NS and PO model of E protein-membrane systems till $5 \mathrm{~ns}$.

F. Box plot showing the comparison of the Electrostatic energy profiles between the NS and PO model of E protein-membrane systems till $5 \mathrm{~ns}$.

G. Box plot showing the comparison of the Vander Waals energy profiles between the NS and PO model of E protein-membrane systems till $5 \mathrm{~ns}$.

$\mathrm{H}$. Box plot showing the comparison of the kinetic profiles between the NS and PO model of E protein-membrane systems till 5 ns.

I. Box plot showing the comparison of the energy profiles due to bond angles between the NS and PO model of E protein-membrane systems till 5 ns.

J. Box plot showing the comparison of the energy profiles due to dihedral angles between the NS and PO model of E protein-membrane systems till 5 ns.

K. Box plot showing the comparison of the energy profiles due to bond lengths between the NS and PO model of E protein-membrane systems till 5 ns.

Fig. 7

A. Principal component analysis (PCA) scatter plot representation of the variability in the dataset along the first two PC axes (PC1- 53\% variability; PC2- 29\% variability). Control and infected samples are orthogonal to each other.

B. MA plot (M-log ratio of fold change; A- mean of normalized counts) for differentially significant gene expression in Infected samples compared to Controls.

C. Volcano plot showing significantly upregulated genes (in orange), significantly downregulated genes (in blue) and non-significantly expressed genes (in black) between infected cells and controls.

D. Barplot showing gene counts of PRKAA1 gene between infected cells and controls. Error bars indicate Standard deviation.

E. Example barplots of differentially upregulated genes between infected cells and controls. The values plotted are gene counts with the error bars indicating 
standard deviation. Genes plotted: CD40, IFNL1, IFNL2, IFNL3, IL12A, IL33, IL6 and NFKB1.

F. Same as E, but for differentially downregulated genes. Genes plotted: HSP90AB1, HSP90AA1 and HSP90B1.

G. Distribution showing the percentage of genes significantly upregulated $(p<$ 0.01 ) and with LFC $>2.88 \%$ of the genes were upregulated while $12 \%$ of the genes were downregulated.

$\mathrm{H}$. Gene enrichment analysis and gene ontology network obtained from upregulated genes in infected samples vs controls showing enrichment for immune functions and its associated signaling pathways. Metascape was used for this analysis. Different colored dots indicate different genes encoding same function.

I. Protein-protein interaction (PPI) enrichment analysis showing cellular functions determined by the upregulated genes in infected samples vs controls. Metascape was used for this analysis. Different colored dots indicate different genes encoding similar protein-protein interactions. 
A

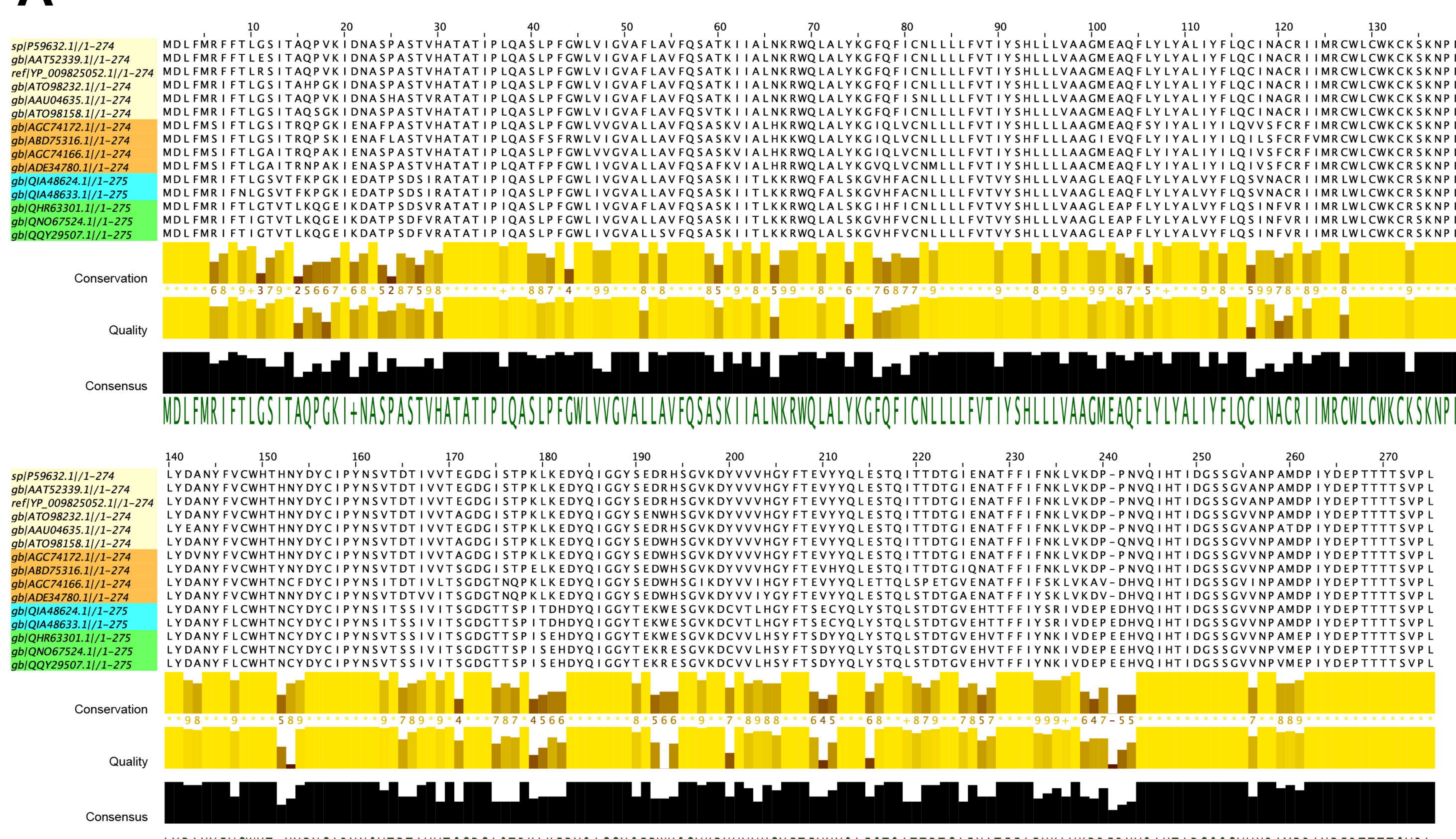

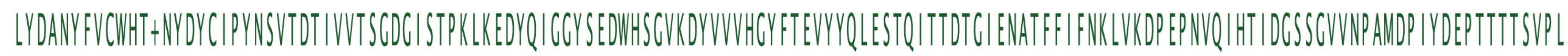

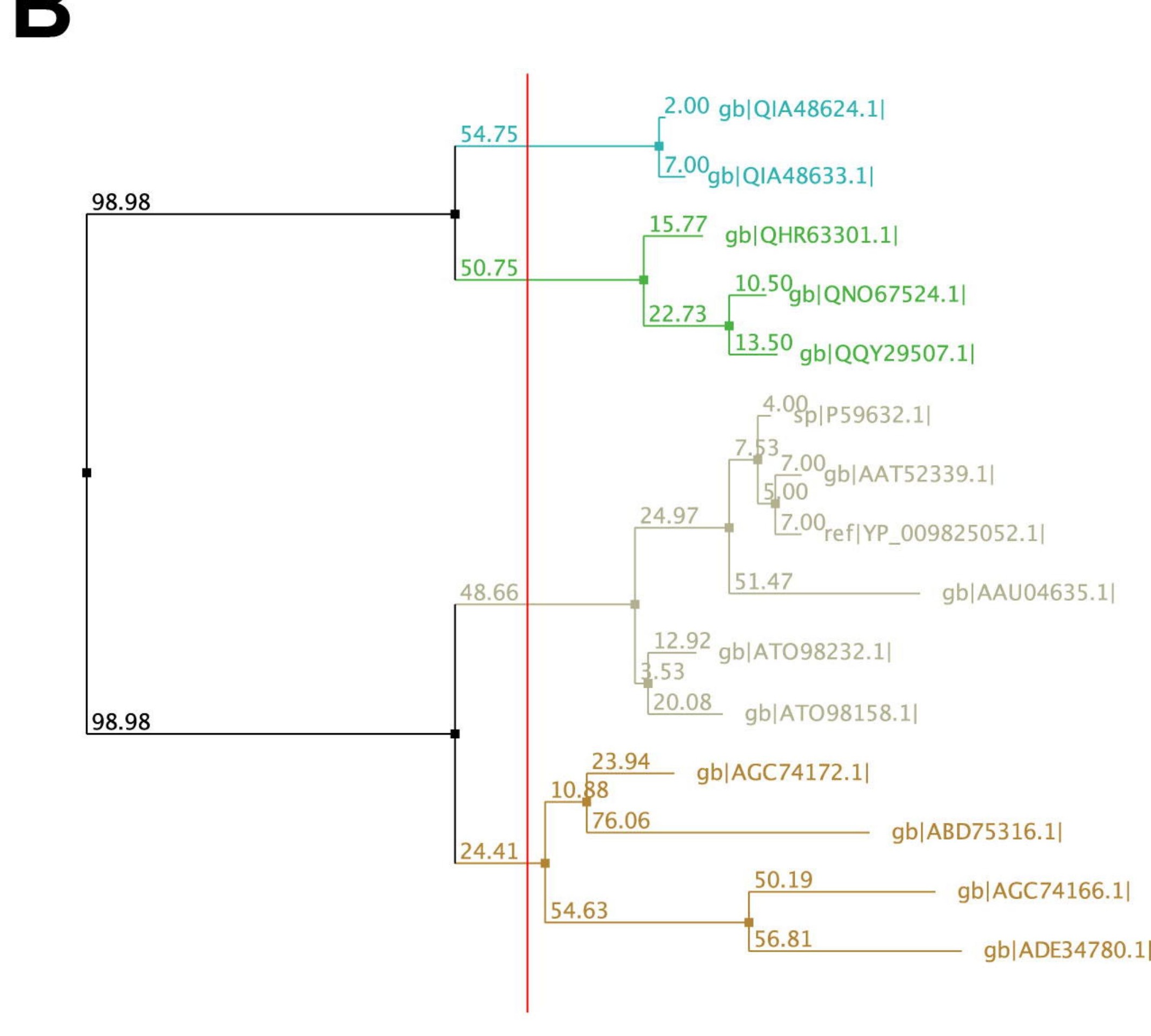

C

ORF3a SARS CoV-1: sp|P59632.1| ORF3a SARS CoV_LLJ-2004 ORF3a SARS CoV_Tor2 ORF3a Bat SARS-like CoV ORF3a Civet SARS-like CoV_007/2004 ORF3a Bat SARS-like CoV ORF3a Bat SARS CoV_Cp/Yunnan2011 ORF3a Bat SARS CoV_Rf1/2004 ORF3a Bat SARS CoV_Rp/Shaanxi2011 Hypothetical ORF3a Bat SARS_HKU3-9 ORF3a Pangolin SARS CoV ORF3a Pangolin SARS CoV ORF3a Bat SARS CoV RaTG13 ORF3a SARS CoV2

\section{Pairwise distance}

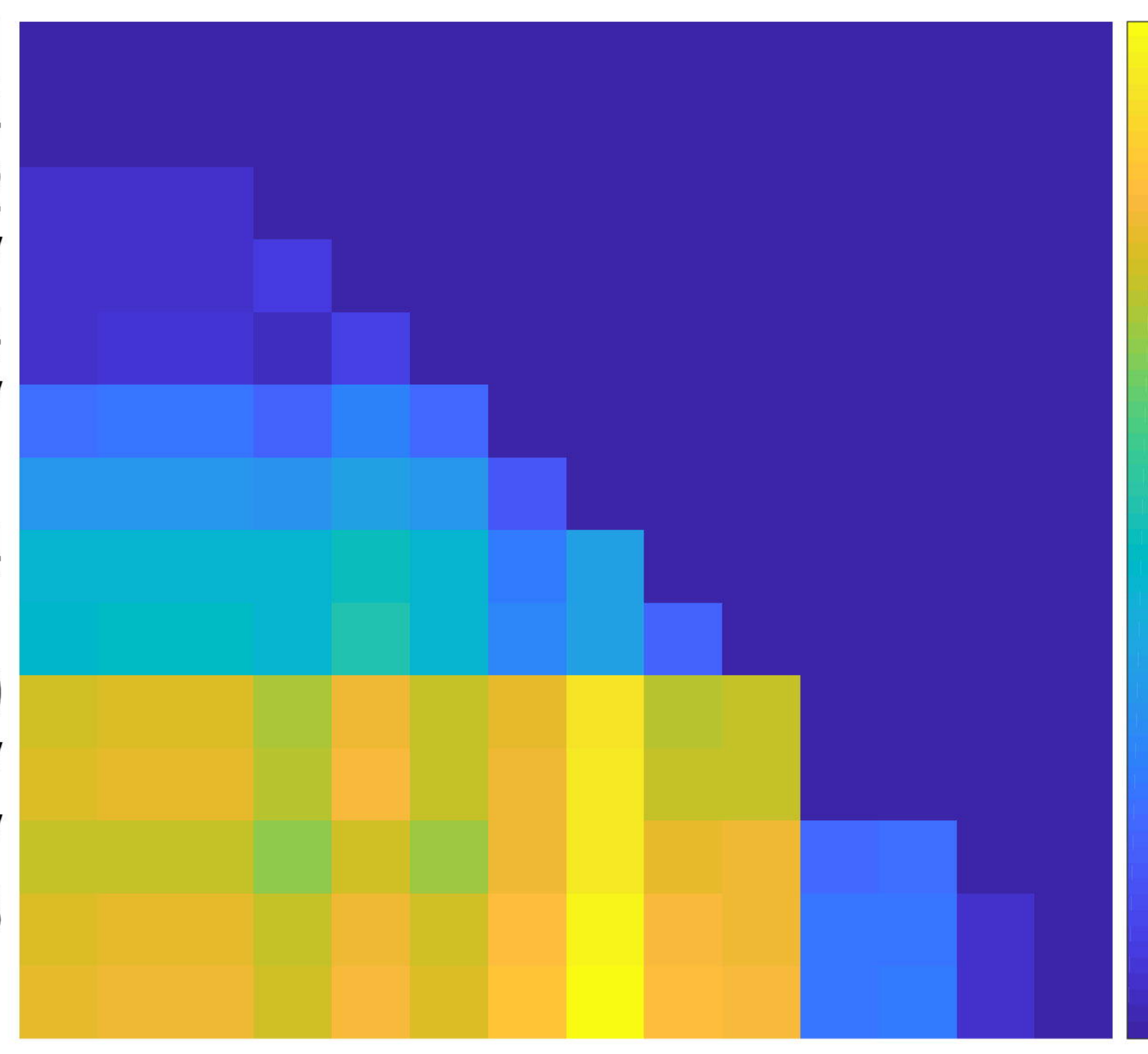

D

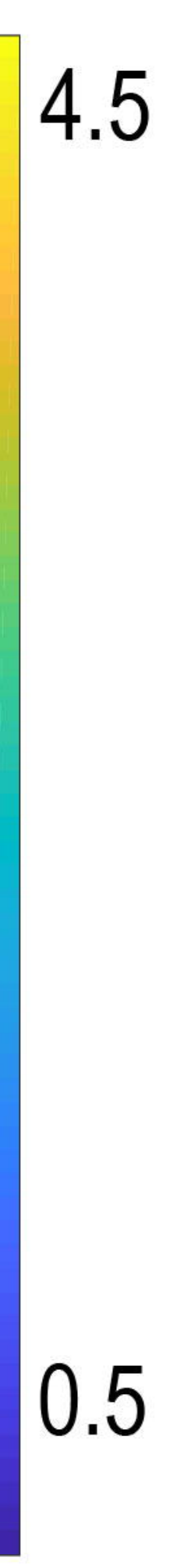

Disparity Index

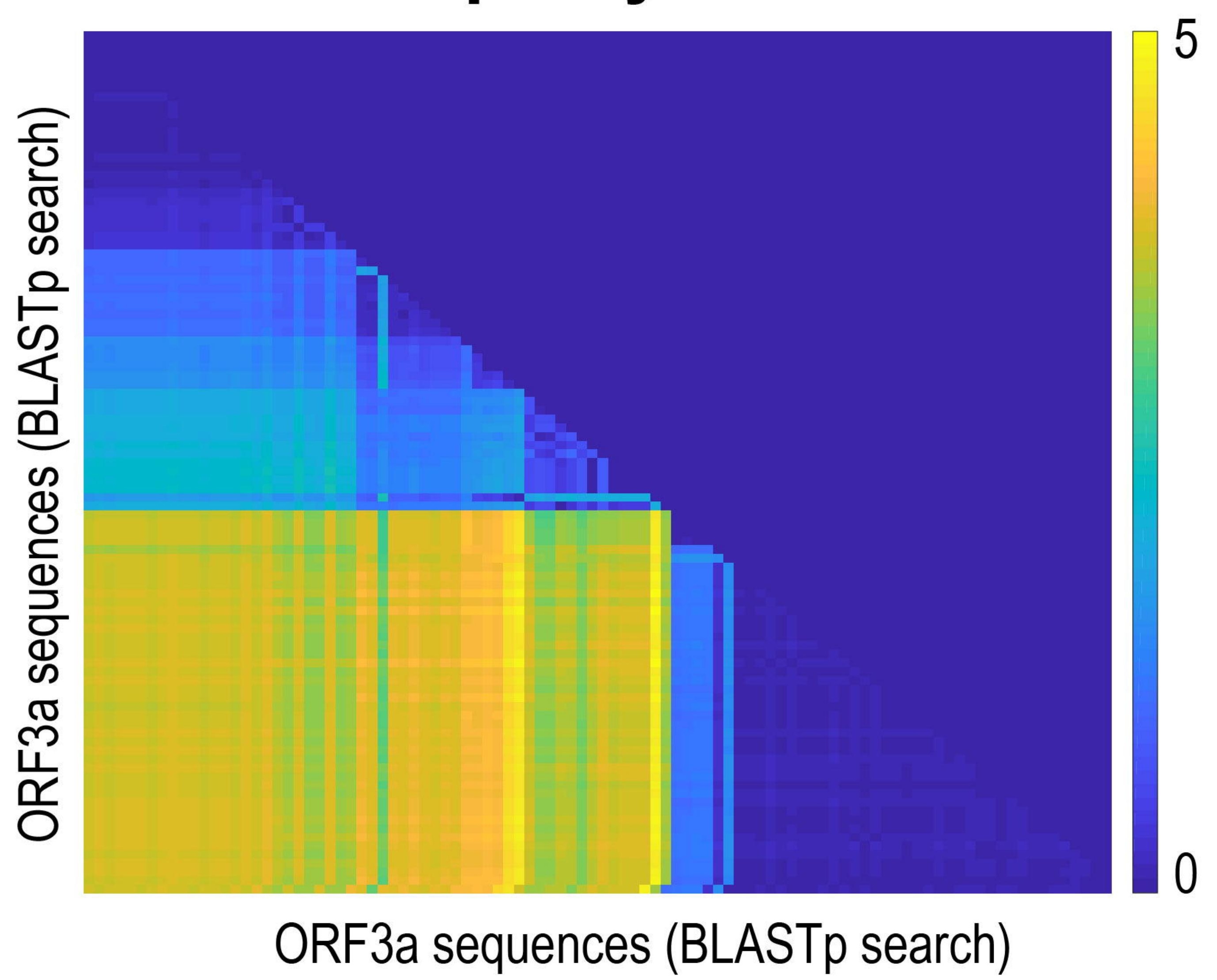


SARSCOV1 SLPFCWLVI GVAFLAVFOSATK I I ALNKRWQLALYKGFQF I CNLLLLFVT I Y SHLLLVAAGMEAQFLYLYALIYFLQCINACR I I MRCWLCWKCKSKNPLL SARScov2 SLPFGWLI VGVALLAVFQSASK I I TLKKRWQLALSKGVHFVCNLLLLFVTVYSHLLLVAAGLEAPFLYLYALVYFLQS INFVR I IMR LWLCWKCR SKNPLL Conservation

Consensus

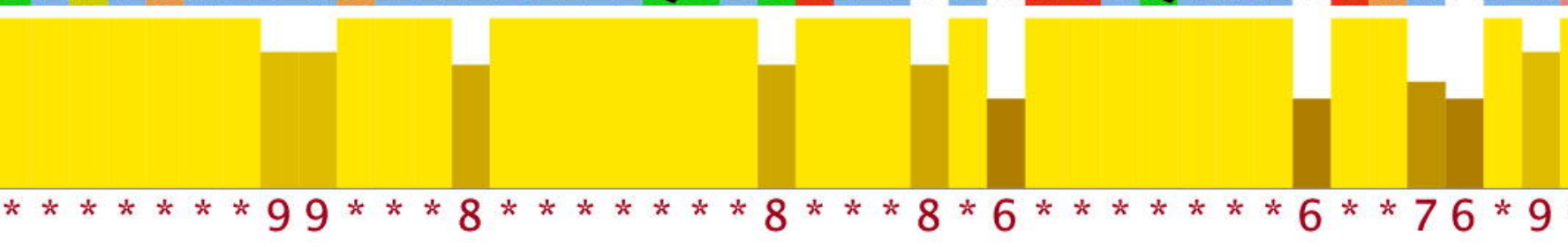

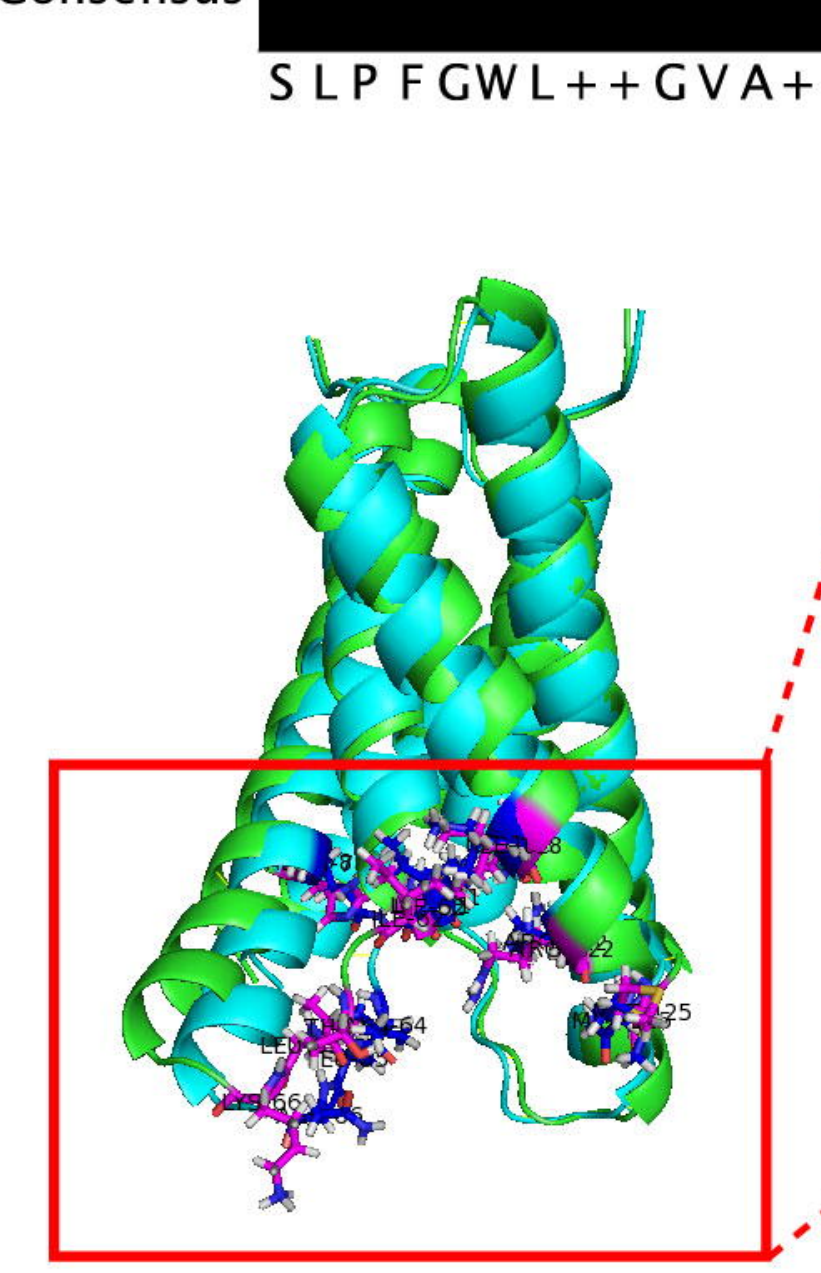

C

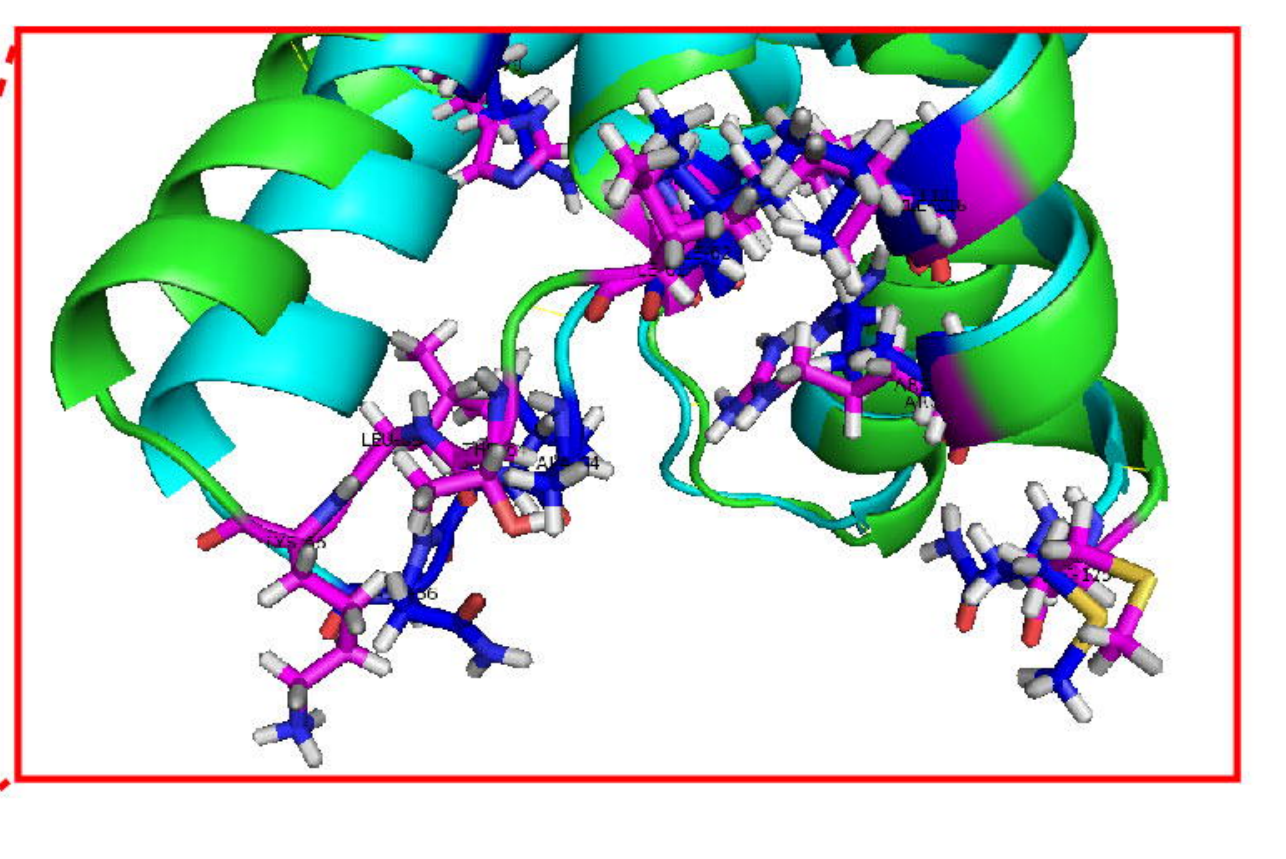

D

SARS CoV1 intersubunit channel

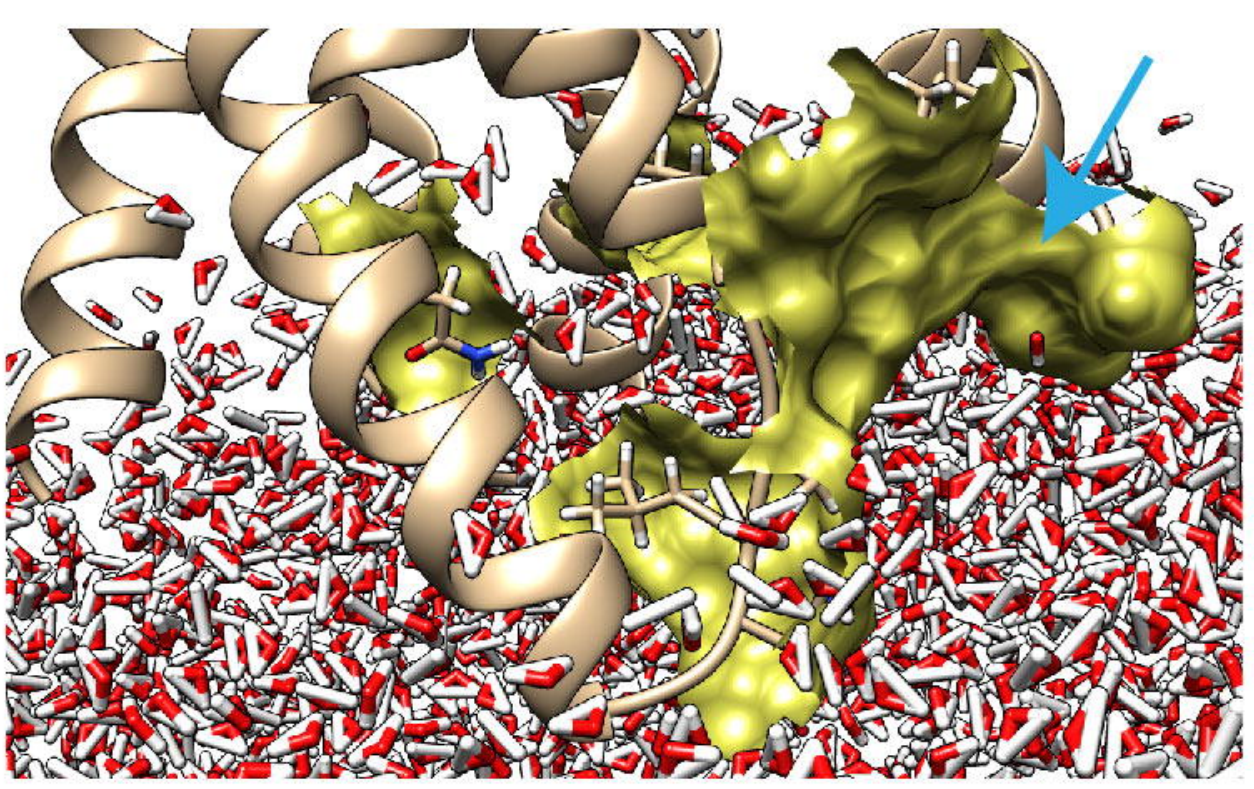

E

EARS CoV2 intersubunit channel

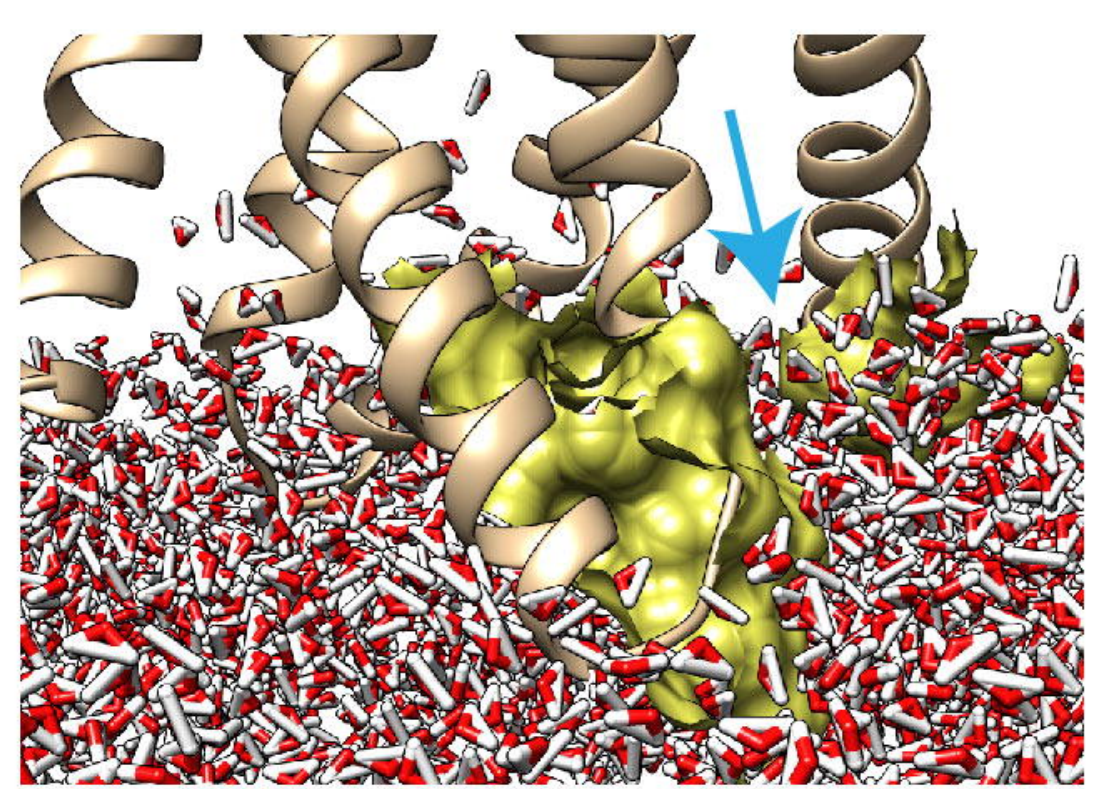

SARS CoV2

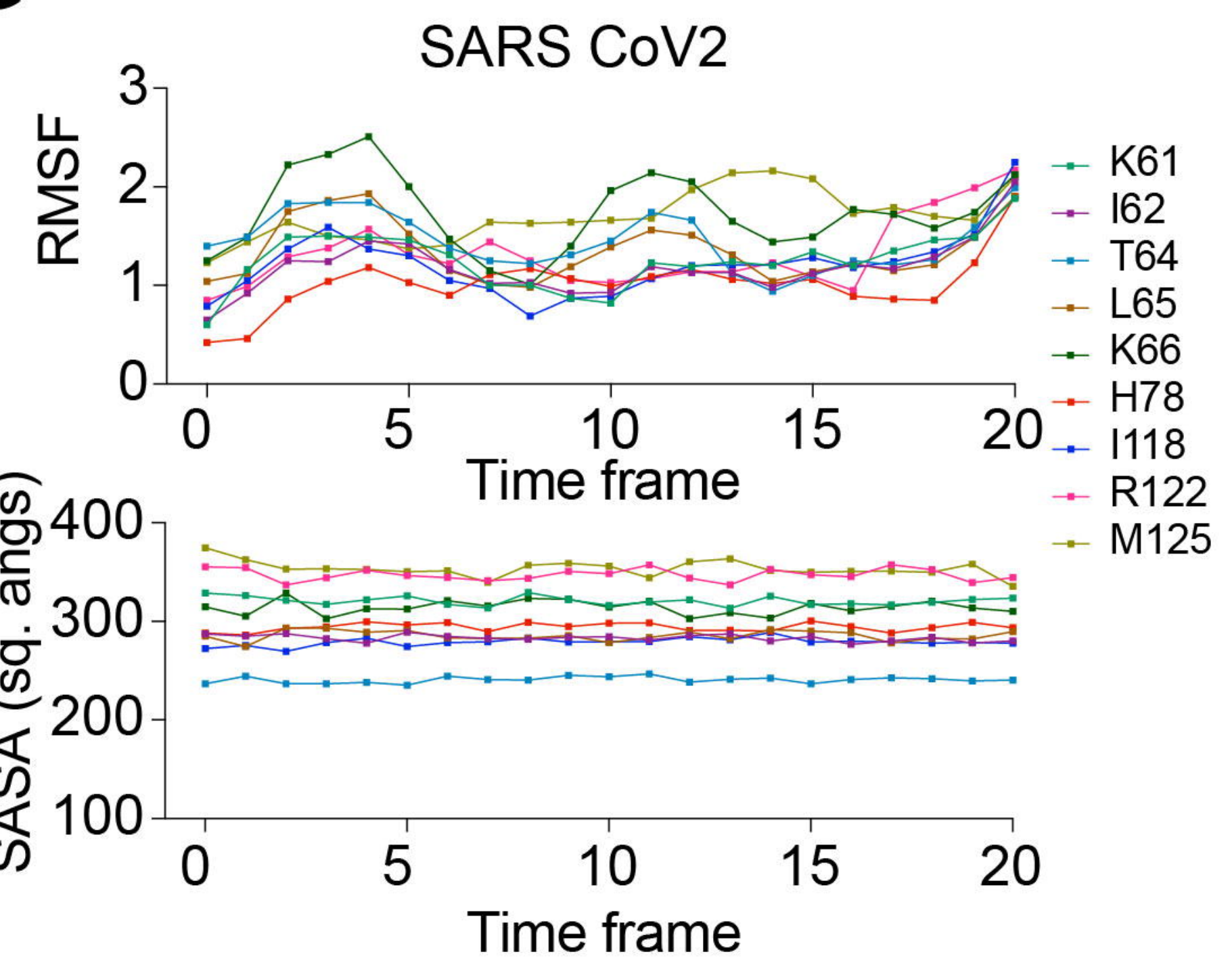

K

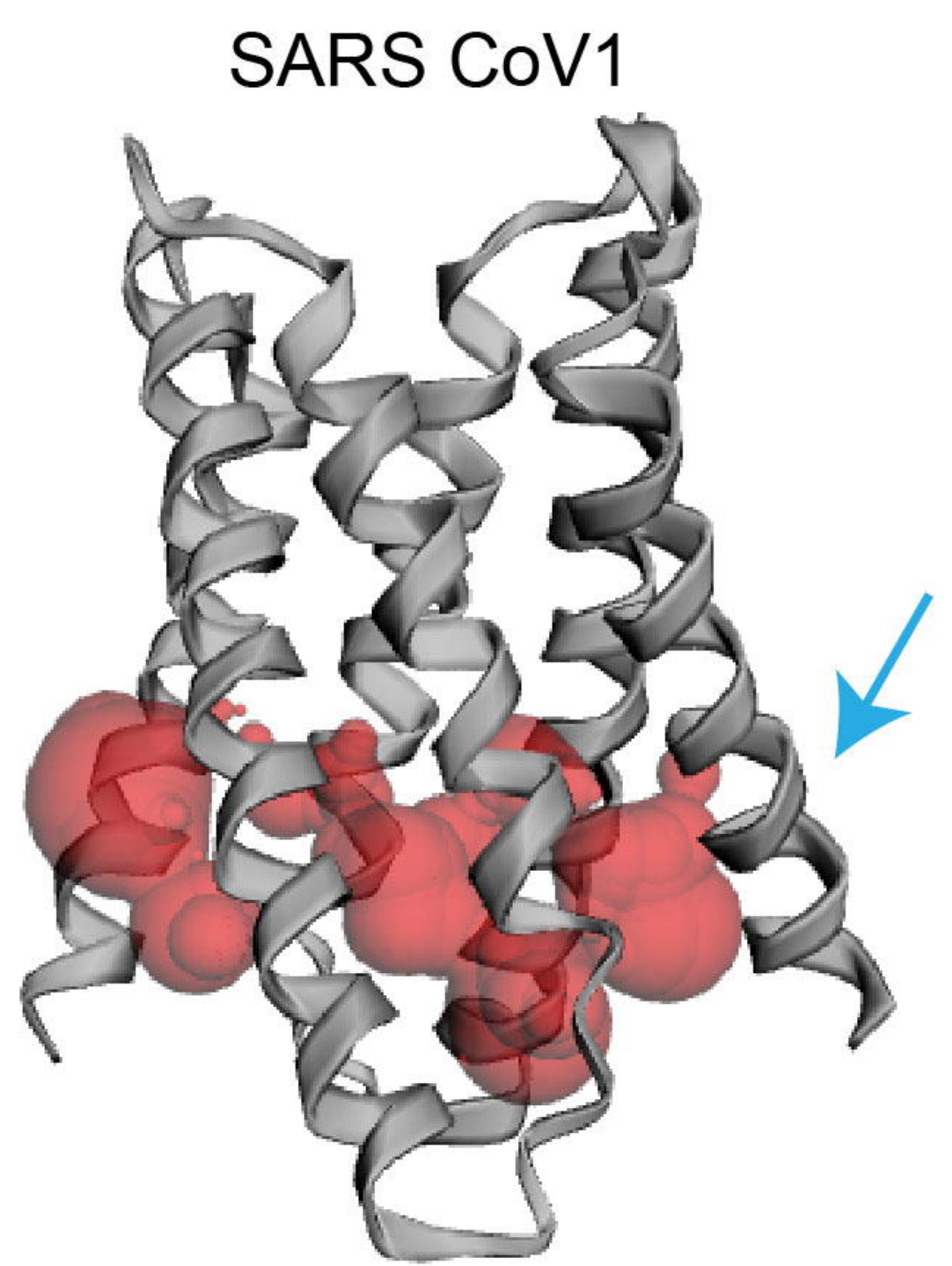

J

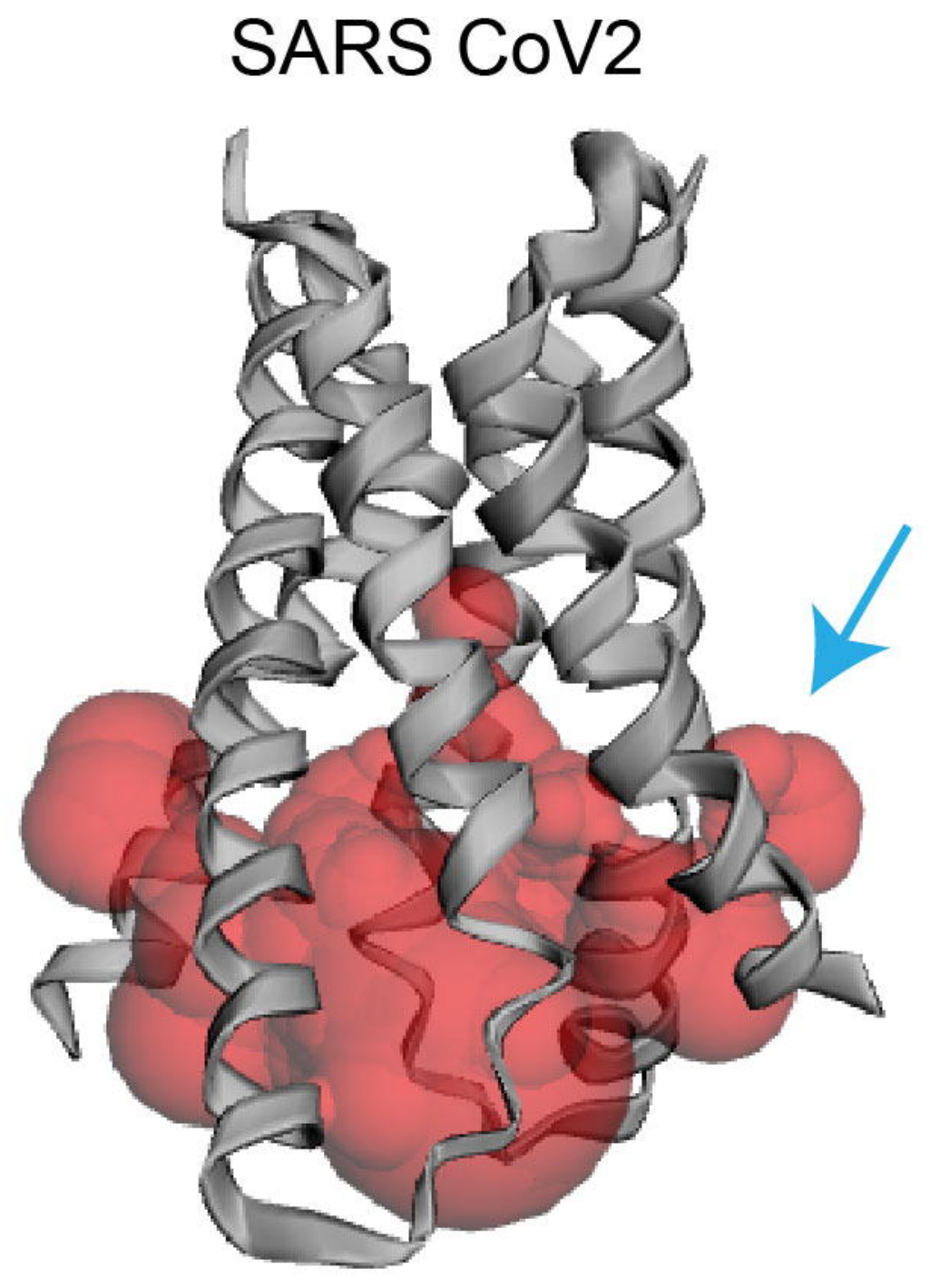

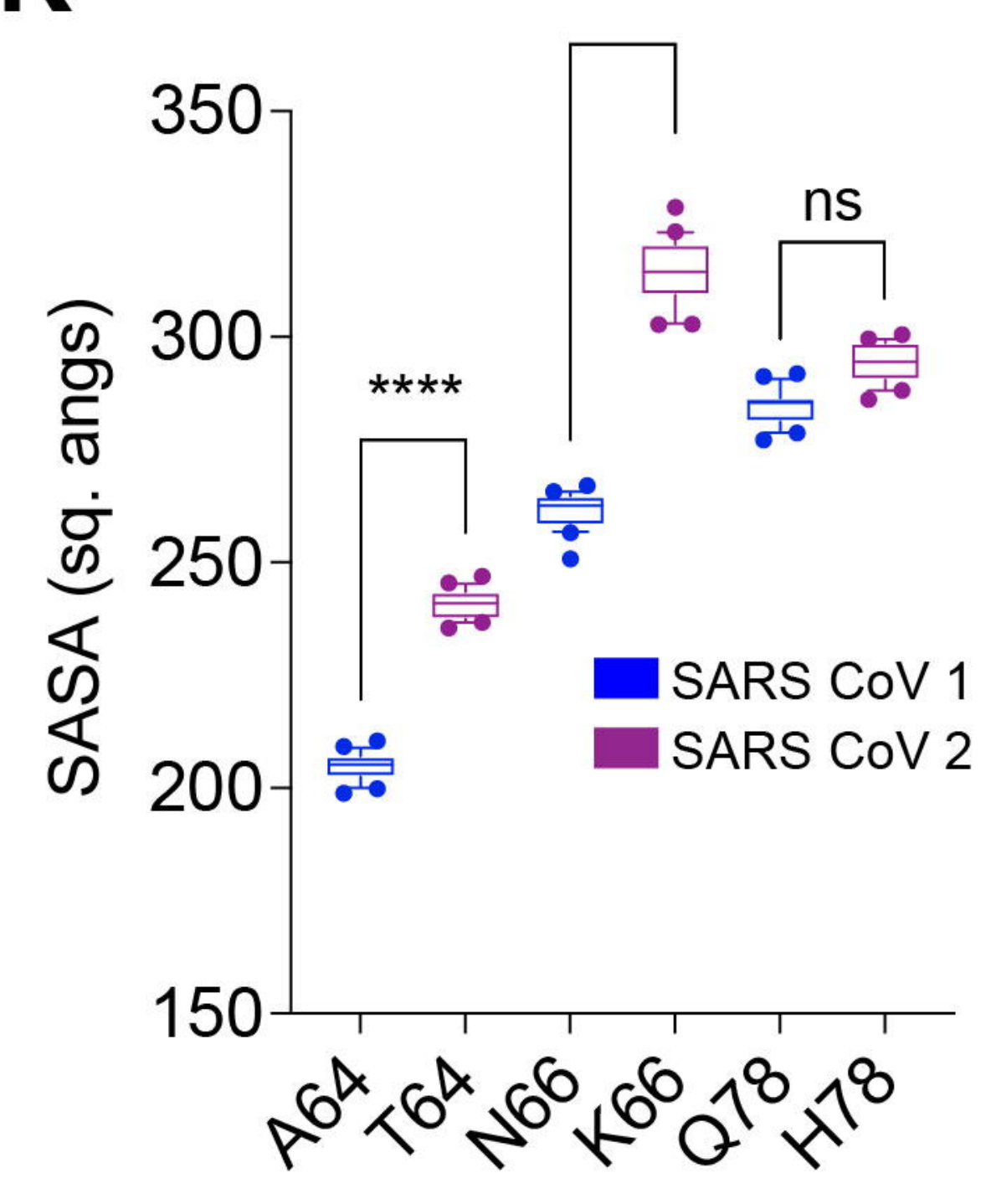

H

Total SASA

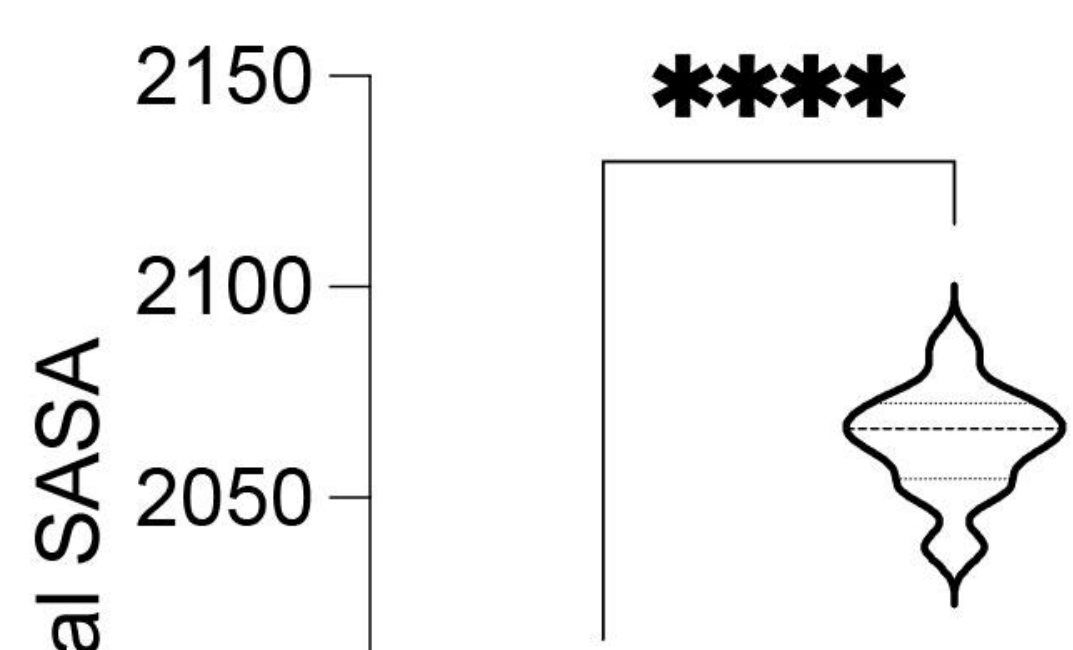

2000

1950

1900<smiles>C1[Te][Te][Te]1</smiles>

Cov1 CoV2

$\mathbf{L}$

Total energy

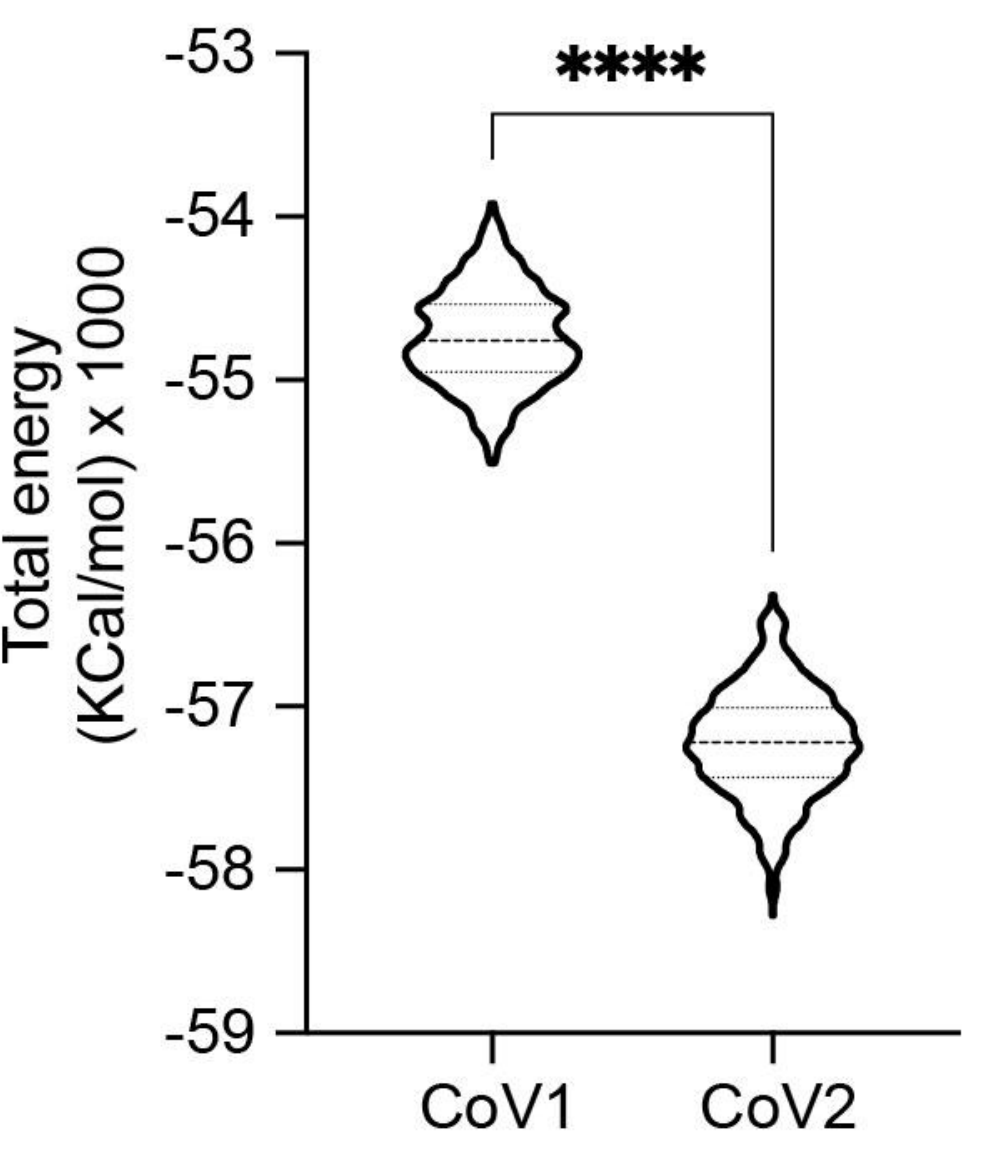




\section{SARS CoV 2 E protein- 8-40 ERGIC}

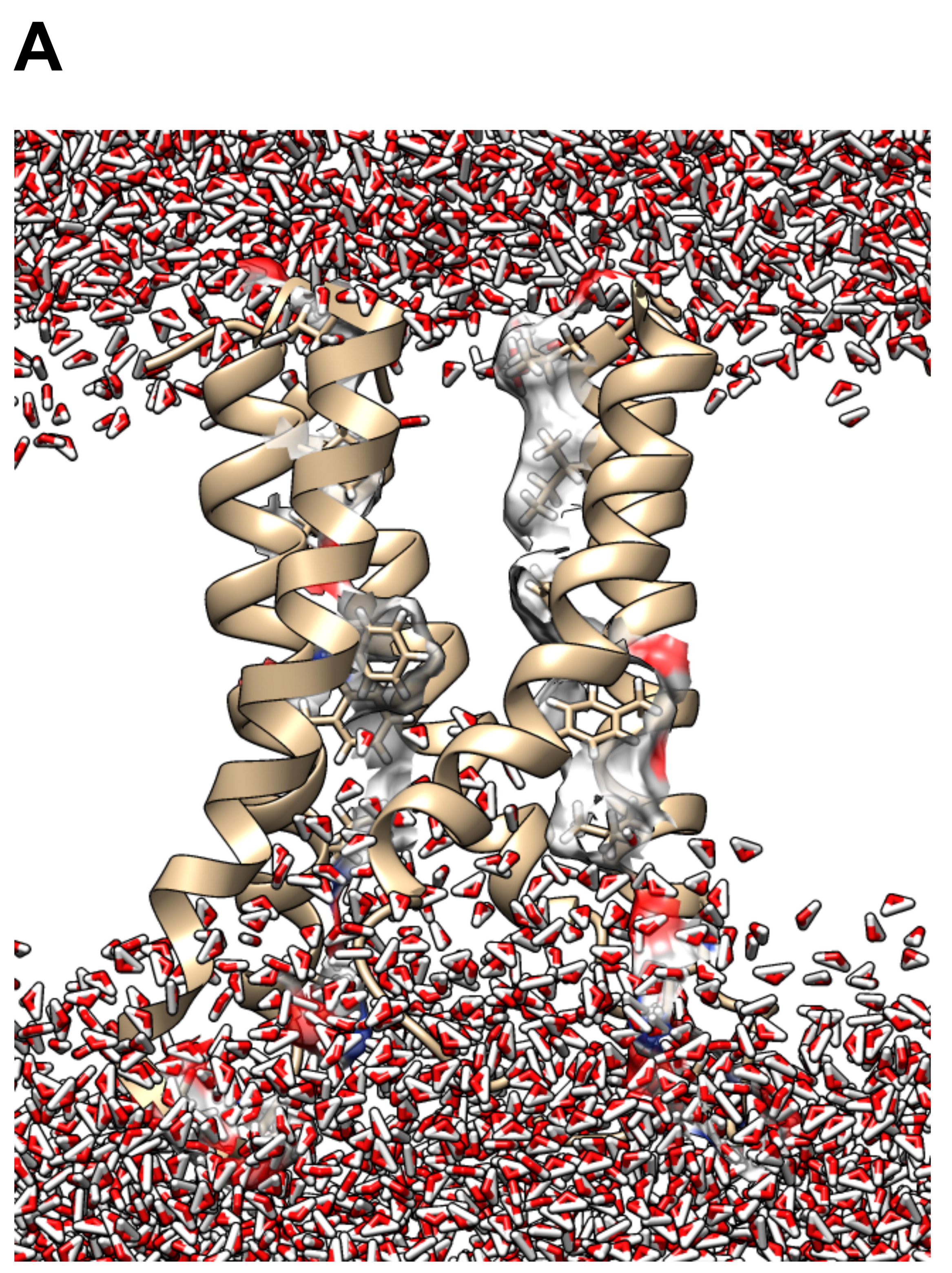

B
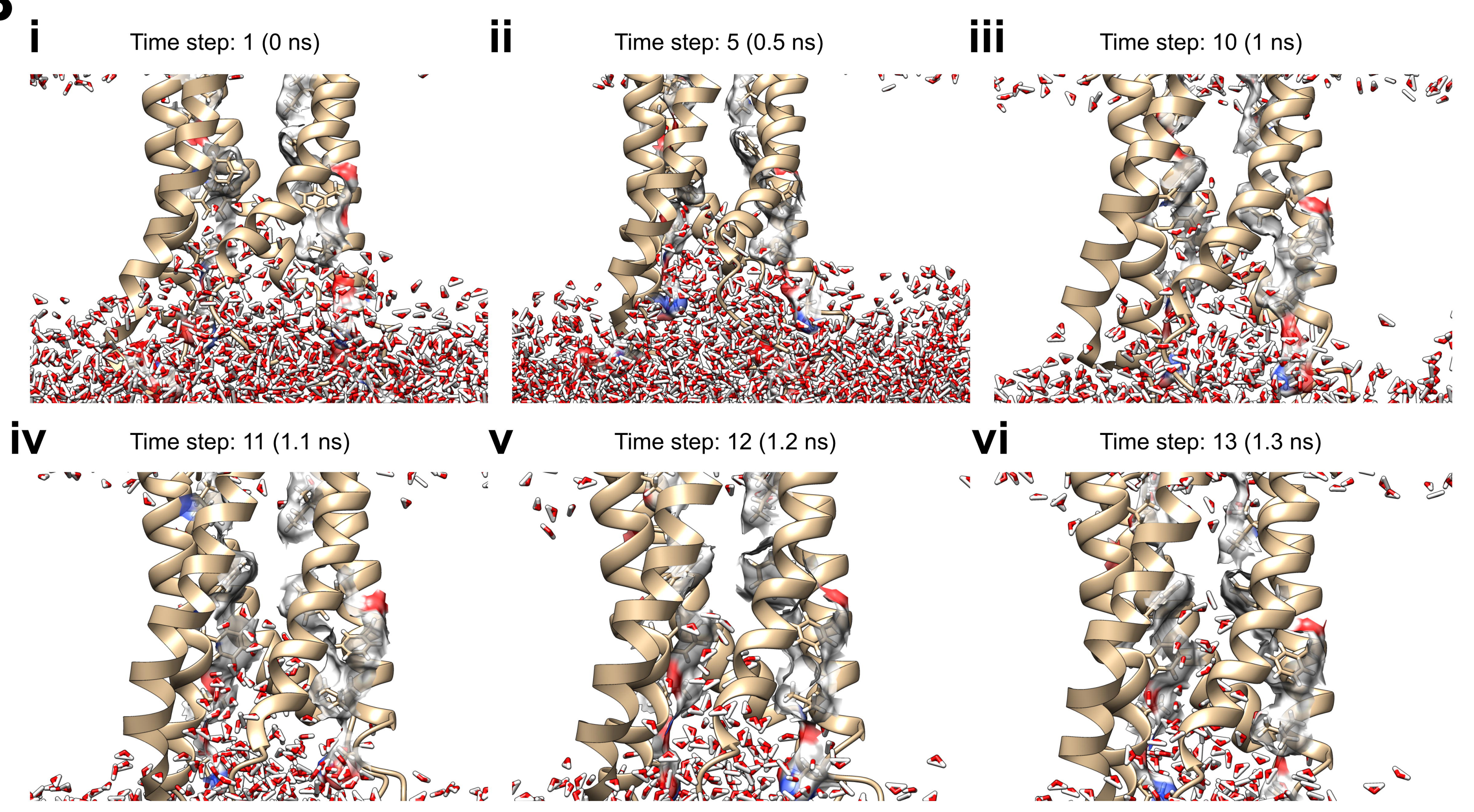

vii

Viii Time step: $15(1.5 \mathrm{~ns}) \quad$ iX

X Time step: 20 (2 ns)

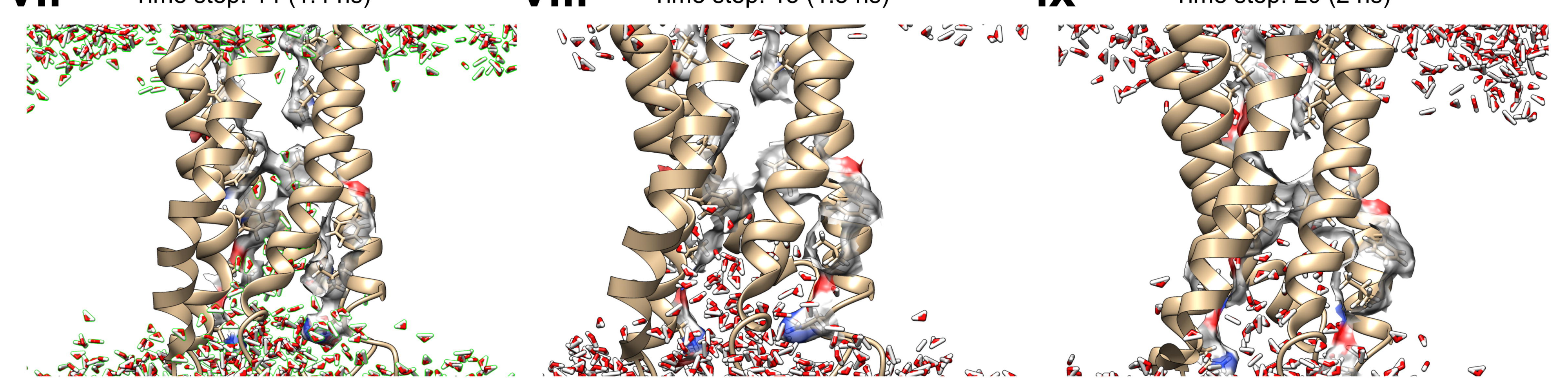

C

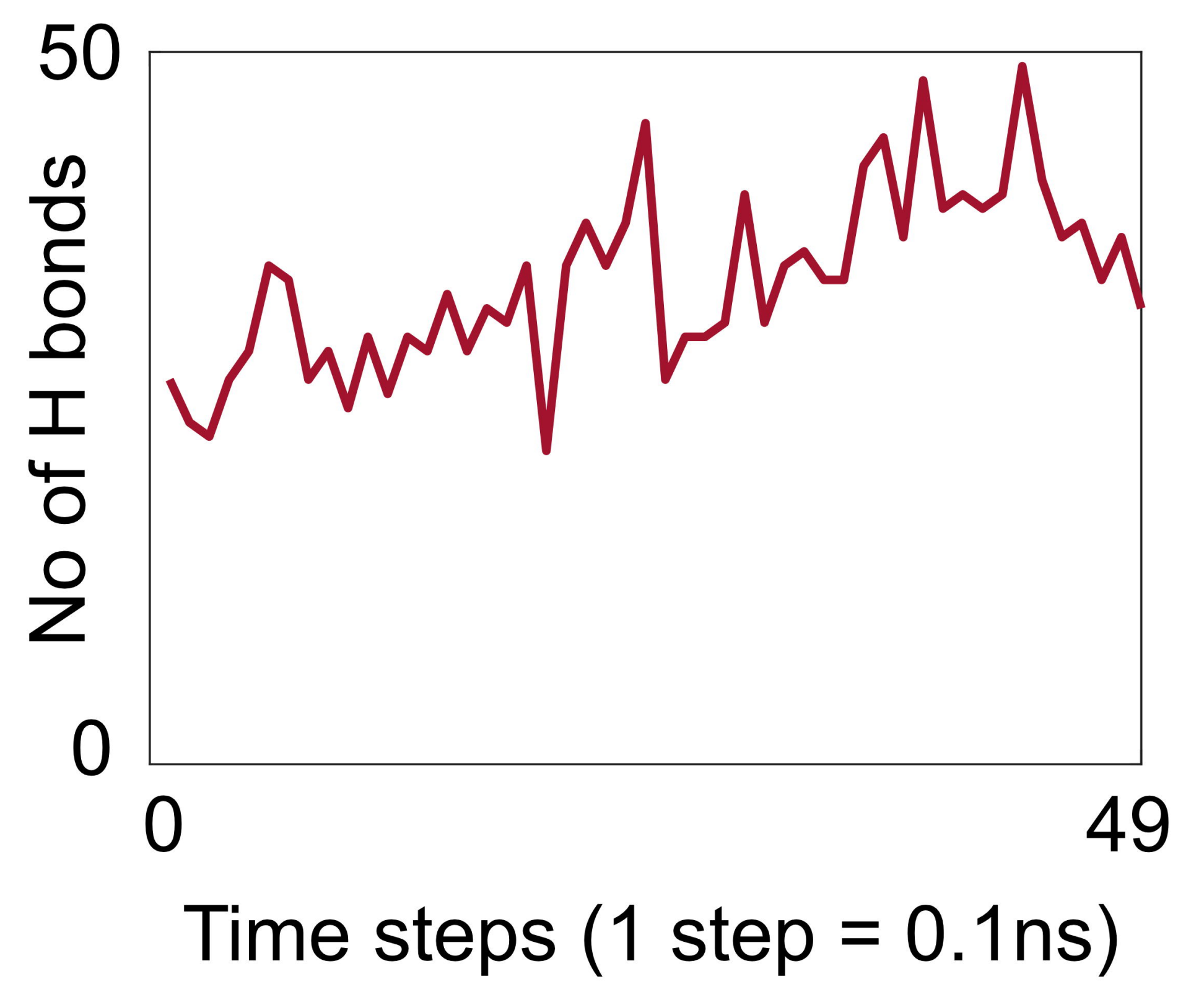

D

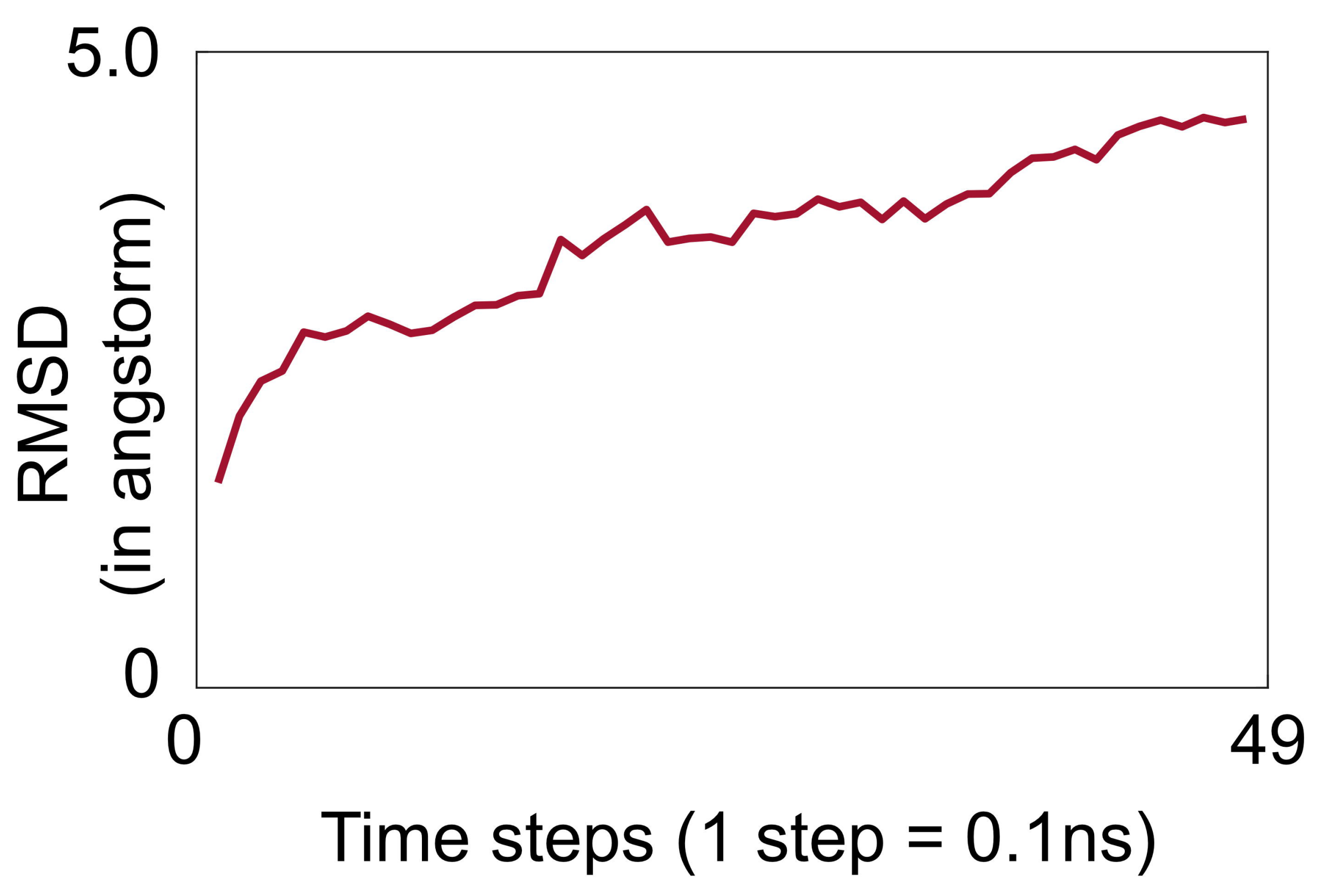

E

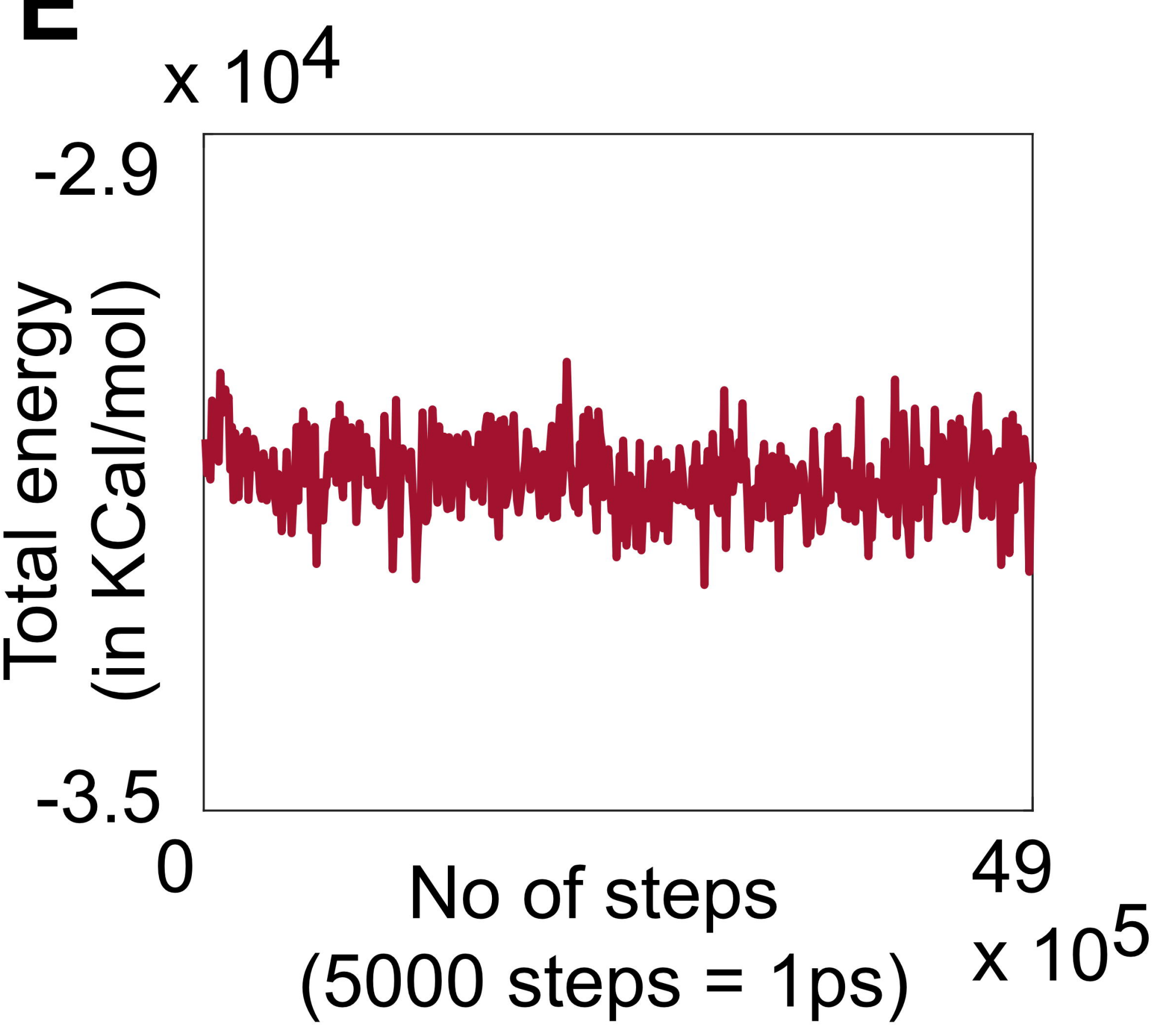

$\mathbf{F}$

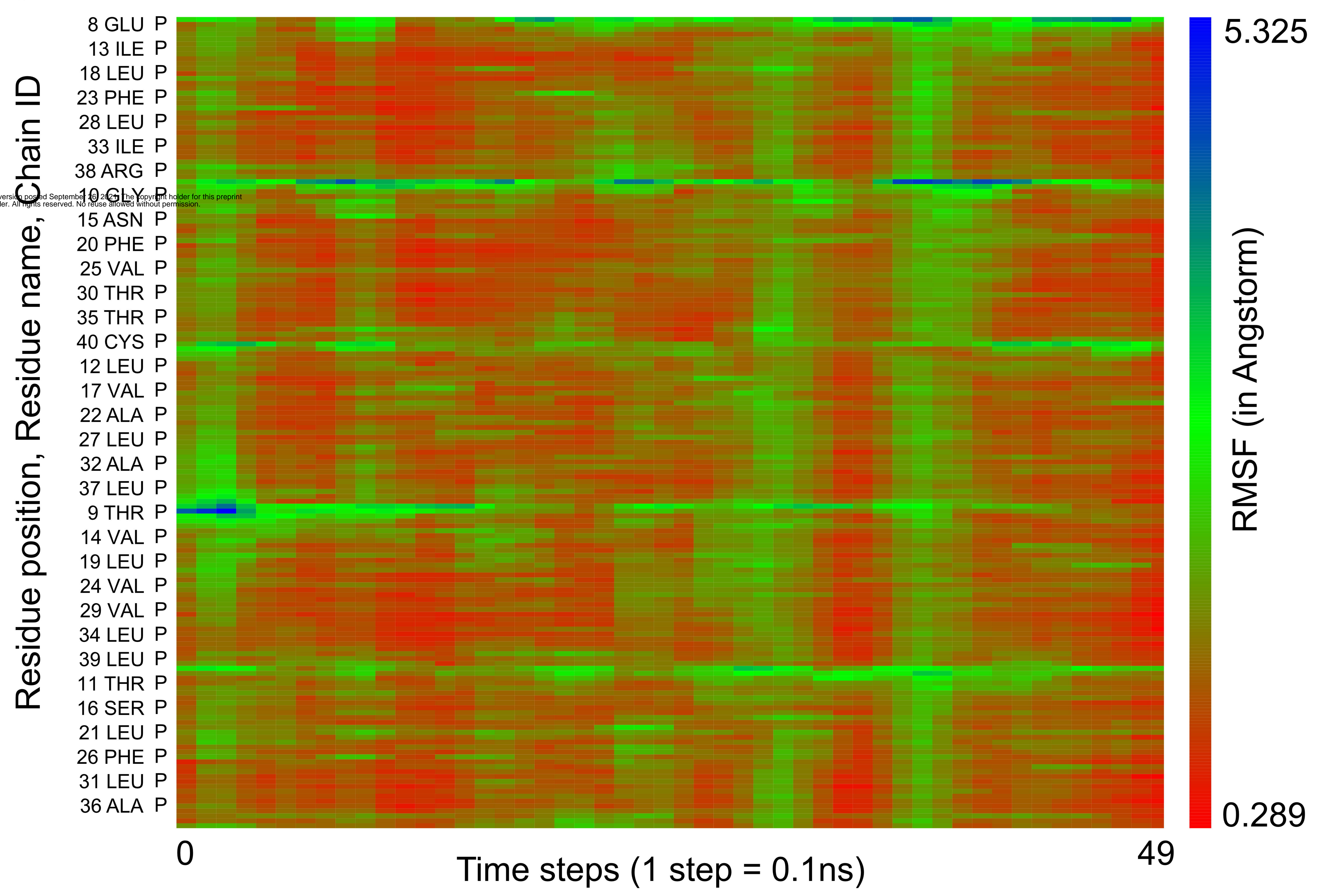


A

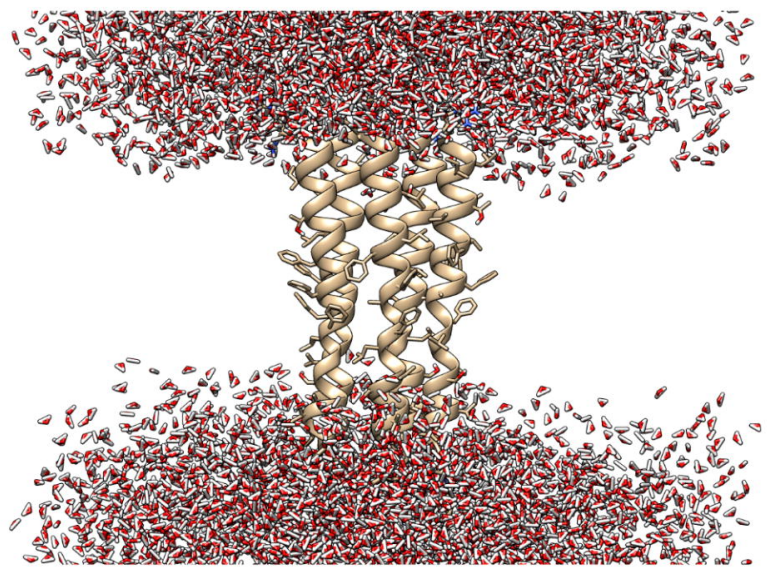

C
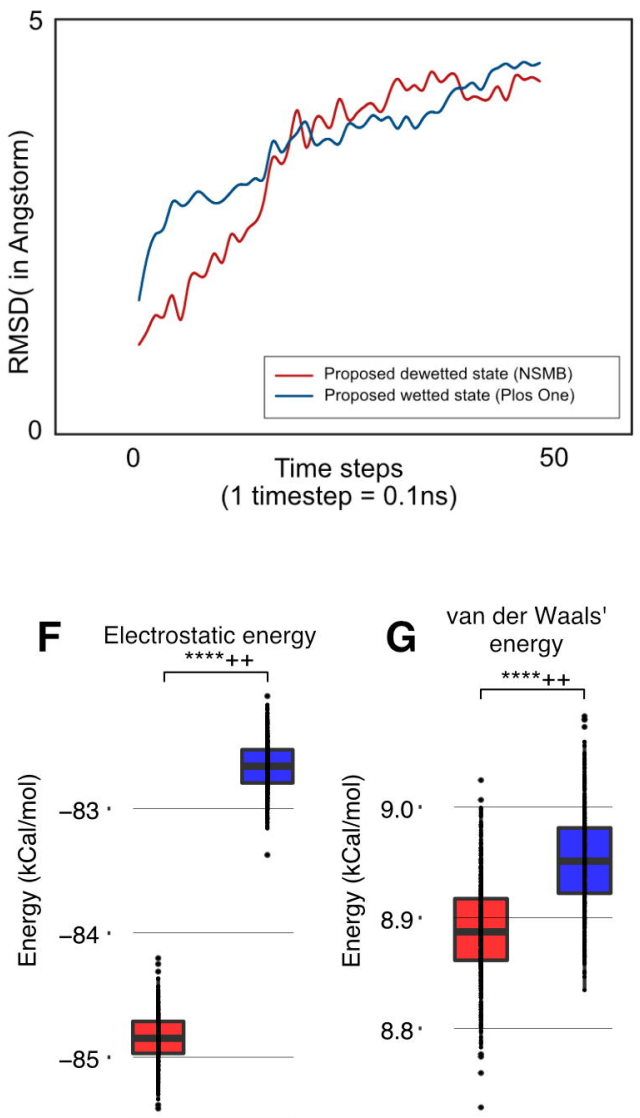

Possible Possible dewetted wetted

B

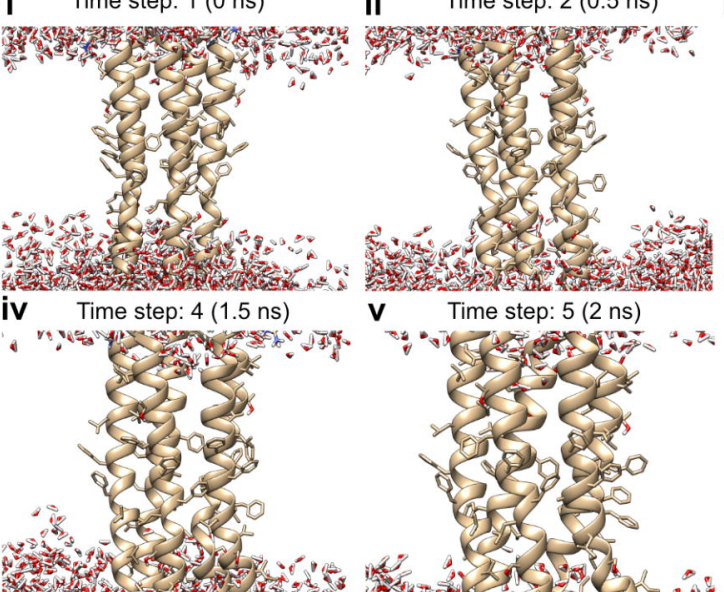

D

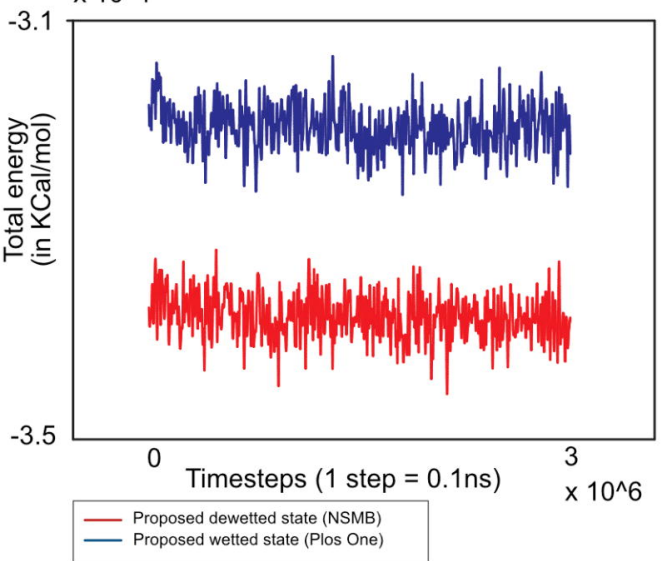

E

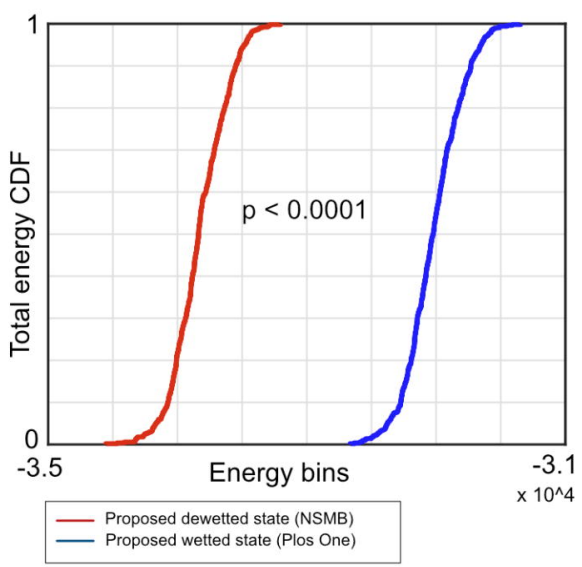

K Bond length energy

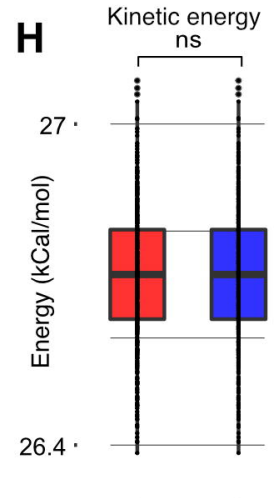

Possible Possible dewetted wetted

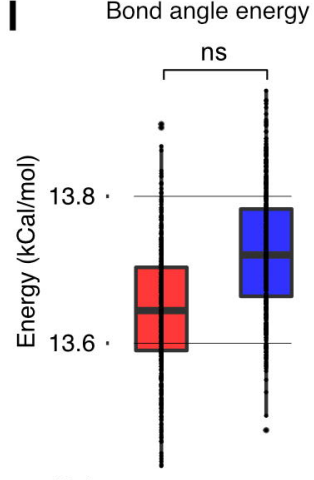

13.4 .

Possible Possible dewetted wetted

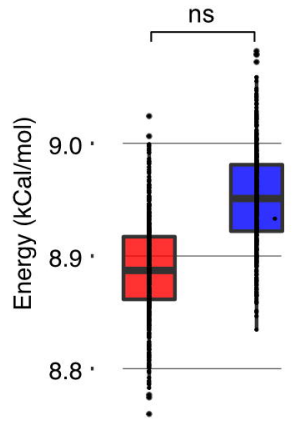

Possible Possible dewetted wetted

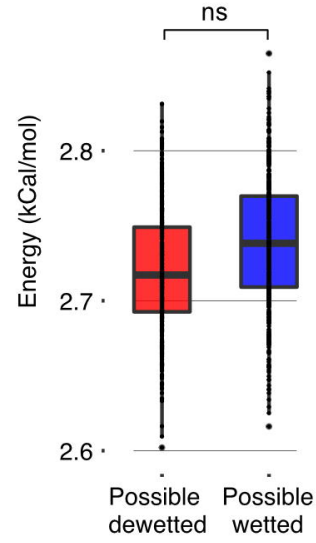


